\title{
FISTULAS UROGENITALES E INCONTINENCIA URINARIA DE ESFUERZO
}

\author{
Doctores B. Neme* y J. R. Azevedo**
}

Teniendo en común la pérdida involuntaria de orina, las fístulas uro-genitales y la incontinencia urinaria de esfuerzo, son sin embargo, entidades distintas desde el punto de vista etiológico, pronóstico y terapéutico.

Desde un principio nos pareció difícil e injustificado su estudio en conjunto, razón por la cual resolvimos tratarlas por separado, siendo el capítulo de las "Fístulas uro-genitales" tratado por B. Neme, y el otro colega el capítulo de "La incontinencia urinaria de esfuerzo".

Atendiendo al espíritu de la ilustre Comisión Organizadora de este Congreso, procuramos presentar el problema en forma global, sucinta y actualizada.

Las referencias bibliográficas relacionadas con este asunto son numerosas; sin embargo, de las referencias por nosotros presentadas, citaremos solamente las publicaciones que son mencionadas en el texto del presente trabajo.

$\mathrm{Al}$ hacer nuestra indicación para este tema, el profesor Octavio Rodríguez
Lima, M. D., Presidente de la Sociedad Brasilera de Ginecología y Obstetricia, una vez más demostró la amistad con que nos distingue y que, en forma respetuosa, retribuímos y agradecemos.

\section{FISTULAS UROGENITALES}

Tema de los más discutidos es el interesante capítulo relacionado con las fístulas urogenitales, que va siendo renovado por el incremento de la ocurrencia de lesiones del tracto urinario, durante intervenciones quirúrgicas y después de irradiaciones, utilizadas en la terapéutica de ginecopatías benignas y malignas.

En esta forma la lesión en las vías urinarias, que en general se presentaba en vejiga, pasó a situarse también en el uréter. De allí la aparición de complicaciones que han abierto nuevas perspectivas en el capítulo que vamos a estudiar y que son presentadas, de forma especial, por las urétero-anastomosis y por la práctica de neovejigas, cuyas técnicas fundamentadas en el conocimiento

* Docente Libre de Clínica Obstétrica y Ginecológica de la Universidad de Sao Paulo. Docente Libre de Clínica Obstétrica de la Facultad Nacional de Medicina.

* Asistente de Clínicas Ginecológica y Urológica de la Facultad de Medicina de la Universidad de Sao Paulo. 
de la fisiopatología de la derivación urinaria, todavía presentan razones que merecen revisión y discusión de conducta en un Congreso especializado.

Presentaremos los siguientes capítulos: I. Etiopatogenia; II. Variedades; III. Síntomas y diagnóstico; IV. Profilaxis; V. Tratamiento, y VI. Pronóstico.

\section{ETIOPATOGENIA}

Cinco son las causas etiopatogénicas: a) el trauma del parto; b) las lesiones quirúrgicas; c) la actinoterapia; d) las lesiones destructivas de naturaleza inflamatoria y, finalmente, e) las fístulas determinadas por otras causas.

a) Fístulas por trauma del parto. En 1934 Frommolt 146-7-Stamatiades afirmaba que el factor tocológico iba cediendo lugar al ginecológico en la etiopatogenia de las fístulas uro-genitales. Así lo es el hecho de que, en los 90 casos internados entre 1926-1932, en la Clínica de Mujeres de la Universidad de Berlín, 64 fueron relacionados a causas ginecológicas. Hecho idéntico se va observando en los grandes centros donde la asistencia obstétrica, reduciendo la duración del parto y aumentando las intervenciones extractivas mal indicadas, limitó la lesión de las vías urinarias a raros casos de lesiones quirúrgicas, en el curso de la operación cesárea segmentaria.

Verificamos en esta forma, considerando datos exclusivamente a partir de 1942 que, en los EE. UU., entre 1.172 casos de fístulas uro-genitales, mencionadas en 8 publicaciones (Latzko-221; Ward-410; Thompson-395 y Counsel- ler; Carter- 67 y colaboradores; Counseller-91 y Haigler-91; Everett 124 y Mattingly; Mc Causland-264 y colaboradores, y Miller-279 y George), la causa tocogénica estuvo presente en un mínimo de $8,6 \%$ y en un máximo de $43,5 \%$ de los casos.

Sin embargo, en India, Brasil y otros países suramericanos (Perú y Argentina), siguiendo el mismo criterio y según los datos de Lucas Machado-238; Krishman-215; Reyes-342; Neme-303, y Gallucci; Azevedo-11; Souza Rudge532; Salgado-363; Burgos-59; Couri-92; Fernández-134 y Leitao; Guixá-161 y Otturi; Lana-219; Salber-358 y Guixá y Thompson, entre 1.431 fístulas, el factor obstétrico ha incidido con un mínimo de $28,9 \%$ y con un máximo en $100 \%$ y, como promedio, más o menos en $90 \%$ de los casos.

Como consecuencia de este análisis, se deduce que las fístulas tocogénicas son frecuentes en los países de gran extensión territorial y como índice demográfico, mientras la incidencia de las fístulas de naturaleza ginecológica va aumentando en los grandes centros, donde el incremento de la actinoterapia y la mayor extensión de las intervenciones quirúrgicas en la cura de las ginecopatías neo-plásicas afecta, cada vez más, la integridad del tracto urinario.

Los mecanismos por los cuales se trata de explicar la etiopatogenia de las fístulas tocogénicas, son dos: la compresión o necrosis y el trauma quirúrgico.

Verdaderamente no es fácil hacer distinción de un mecanismo al otro, habiendo situaciones clínicas en las cua- 
les los dos factores pueden estar en juego. En una primera fase, la compresión prolongada de los tejidos maternos determinaría su mortificación $\mathrm{y}$, como consecuencia, menor elasticidad y resistencia. En seguida, y por cuenta de la distensión moderada o normal, el tejido se rompe al lesionarse con ocasión de la progresión espontánea o extractiva del producto de la concepción.

Por otro lado, en los partos prolongados, cuando la cabeza del feto se detiene a nivel del canal pélvico por 3 o más días, se puede verificar la eliminación de la escara de necrosis, inmediatamente después del parto, conduciendo a la confusión de una fístula por necrosis con aquella originaria por heridas del tracto urogenital.

La localización de las fístulas tocogenéticas por necrosis corresponde, en general, a la base de la vejiga, por delante o por detrás de la desembocadura de los uréteres, los cuales casi siempre escapan a la lesión, y del lado genital, a la mitad superior de la vagina. En ciertos casos pueden comprometerse el cuello vesical y la uretra, así como la mitad inferior de la vagina y aun el cuello y porción yuxtacervical del cuerpo uterino. La lesión de la uretra es, por cierto, frecuente; Mahfouz-241 verificó, en el examen de 100 fístulas, lesiones en más de la mitad de los casos. Hecho idéntico fue observado entre nosotros por Souza Rudge-352; Azevedo11; Salgado-363 y Lucas Machado-238, respectivamente en $20,6 \% ; 16,75 \%$; $33,1 \%$ y $14,5 \%$ de los casos.

Malpas-244 y colaboradores, utilizando radiografías de gestantes a tér- mino y al comienzo del trabajo de parto tomadas con previa inyección de medio de contraste en la vejiga y uretra, verificaron que, en estos casos, el cuello vesical ocupa una posición constante. Se encuentra a $2-3 \mathrm{~cm}$. por detrás de la sínfisis púbica a la altura de la línea hacia arriba y hacia atrás, alcanzando la base de la vejiga en ángulo recto.

A medida que progresa el parto, estas estructuras sufren un movimiento de elevación, siempre limitado, y una rotación para adelante que las acerca a la cara posterior de la sínfisis. De allí la aparición del ángulo vésico-uretral, quedando la uretra y la base de la vejiga orientadas según una misma línea recta, paralela a la cara posterior de la sínfisis púbica.

La amplitud del dislocamiento a que nos referimos, es variable. Mínimo en las pelvis amplias y máximo en los casos de desproporción céfalo-pélvica, pudiendo el cuello vesical alcanzar entonces hasta el borde superior de la sínfisis.

Anomalias pélvicas: El piso pélvico que dificulta el tránsito de la presentación, favorece la compresión de estos segmentos genito-urinarios, más por la duración que por la intensidad (Mahfouz 241 ), contribuye a la isquemia y mortificación de los tejidos $\mathrm{y}$, consecuencialmente, a la aparición de las fístulas por necrosis.

La afirmación que Fritsch-145 y Sim, citado por Miller-278, de que en la etiopatogenia de las fístulas tocogénicas tendría mayor importancia la expectativa que la tendencia intervencionista, encuentra acierto en los datos de Mah- 
fouz-240, Souza Rudge-352, Salgado363 , Salgado-238 y uno de nosotros ( $B$. Neme-302), según los cuales los factores de necrosis por compresión están presentes, respectivamente, en $95 \%$; $88,1 \% ; 49 \% ; 83,6 \% ; 90,5 \%$ y $62,1 \%$ de los casos observados.

Sábese desde hace mucho tiempo que las anomalias pélvicas son de frecuente ocurrencia entre las portadoras de fístulas tocogénicas, por su acción frenadora de la progresión fetal. Es apenas extrañable que hasta 1953 ningún estudio radiológico hubiese sido hecho en relación con las pelvis de estas pacientes. Aun desde el punto de vista cí́nico eran muy imprecisas las referencias bibliográficas a las características dimensionales y morfológicas de estas pelvis.

Para Zangemeister, citado en Stoeckel-384, tendrían importancia fundamental para el desarrollo de la necrosis de compresión, la forma y el tamaño del estrecho superior. El caso sería más grave en la pelvis plana que en las regularmente estrechas, porque en aquéllas la compresión se haría por la sínfisis, mientras en éstas úitimas la misma compresión se distribuiría por área relativamente grande del estrecho superior.

Idéntica opinión fue hecha por Bumm -58 y en general repetida en los demás textos y publicaciones referentes al asuto (Souza Rudge-352, Azevedo-11 y Ahumada-2).

En 1953, uno de nosotros (B. Neme254) en colaboración con Paula Martins y Gallucci, tuvo la oportunidad de practicar radio-pelvimetrías por la técnica de Thoms-Wilson, complementada por la de Allen, en 19 portadoras de fístulas tocogenéticas por necrosis, internadas en la Clínica Ginecológica de la Facultad de Medicina de U. de Sao Paulo, servicio de profesor Medina. Pudimos verificar que en 16 de las pacientes había anomalías pélvicas; la predominancia de la constricción del estrecho medio, en frecuencia e intensidad, sobre los estrechos superior e inferior, mostró que a esta distocia debe caber la mayor responsabilidad en la etiopatogenia de las fístulas por necrosis.

Moir-292, en 1961, también verificó que el aplanamiento de la pelvis, muy raramente estuvo en juego; sin embargo, la presencia de arco púbico agudo fue la regla. Como esta condición frecuentemente se asocia a la reducción del estrecho medio, la observación de Moir viene a confirmar los datos radiopelvimétricos referidos por uno de nosotros (Neme-254).

Todas las intervenciones obstétricas, cuando son mal conducidas, pueden lesionar al septo-urogenital. Al principio el accidente era más común en el curso de la vía baja (aplicación de fórceps, embriotomías y sinfisiotomías); con la gran difusión de la operación cesárea ha aumentado el número de fístulas vésico-vaginales atribuídas a la lesión directa (incisión) o indirecta (disección vesical excesiva a la propagación de la incisión uterina e inclusión de la vejiga en la sutura miometrial). Lucas Machado-236 refiere que el accidente ocurrió 9 veces en 17 casos de fístulas tocogénicas por trauma quirúrgico.

Tales fístulas, como uno de nosotros también lo observó (J. R. A.-18), se asientan, por lo general, en la cúpula vaginal y son de difícil acceso. 
b) Fístulas debidas a la cirugía ginecológica. A medida que las intervenciones ginecológicas, para la cura de las neoplasias benignas y malignas, ganan amplitud, la incidencia de las fístulas urogenitales ha aumentado.

La histerectomía total simple y la histerectomía con salpingooforectomía representa el procedimiento quirúrgico que más frecuentemente lleva a la lesión del tracto urinario, y el estudio de las heridas uretrales que ocurren en operaciones ginecológicas representa, según Everett-121, el más importante eslabón de unión entre la ginecología y la urología.

La incidencia de estas lesiones ureterales no tiende, aun con el desarrollo de la técnica quirúrgica, a disminuír; Wertheim-268 en 1911, durante la intervención que lleva su nombre, encontraba esta incidencia en un porcentaje de 9,3\%. Meigs-268, 45 años después refiere la lesión en 10,9\%, y entre nosotros, del Departamento de Obstetricia y Ginecología de la U. S. P., servicio del Profesor Medina, fue comprobada en $11,02 \%$ en la cirugía amplia de 528 casos de $\mathrm{Ca}$ del cuello del útero.

En el curso de la cirugía ginecológica, mientras la vejiga y el uréter pueden ser alcanzados por las vías abdominal y vaginal, la uretra lo será cuando esta última fuere la escogida. Sin embargo, es en la vía abdominal, en las operaciones radicales para el tratamiento del $\mathrm{Ca}$ del cérvix, donde las lesiones de la vejiga y del uréter son más frecuentes. En su tiempo, Peham-319 y Amreich (1934) verificaron que la incidencia de fístulas urinarias alcanzaban un porcentaje de
$12 \%$ entre las pacientes operadas por la vía abdominal y se reducía a $5.8 \%$ cuando la operación era ejecutada por la vía vaginal.

En las lesiones ureterales, sea por lesión directa (ligadura, sección parcial o total, resección de segmento) o, 10 que es más frecuente, por lesión indirecta (necrosis isquémica consecuente a la extensa disección del uréter), el accidente evoluciona hacia la fístula o hacia la estenosis ureteral. Desde el punto de vista pronóstico, las fístulas son más benignas por cuanto no determinan alteración de la función renal.

Las lesiones del septum vésico-vaginal son más raras y generalmente se deben al trauma directo (sección con ocasión de la disección de la vejiga), o indirecto (necrosis isquémica consecuente a la exéresis excesiva del conjuntivo pélvico), que ocurre en las intervenciones ampliadas para la cura de ginecopatías benignas (Histerectomía total) y malignas (Histerectomía de Wertheim) del útero. Las fístulas consecuentes a lesiones directas practicadas durante intervenciones realizadas por la vía abdominal o vaginal, son menos frecuentes en virtud del fácil reconomiento y de la evolución favorable de la sutura en estas lesiones. En favor de esta afirmación hablan los datos del Servicio donde trabajamos, en donde la ocurrencia de fístula vésico-vaginal no sobrepasó $1,57 \%$ en 528 operaciones de Wertheim.

Sin embargo, cuando la intervención es ampliada, su aparición por necrosis isquémica es más común, y Brunschwig -56 y Frick refieren la alta incidencia 
de $11 \%$ entre 212 intervenciones radicales para el tratamiento del cáncer cervical avanzado.

c) Fístulas consecutivas a la actinoterapia. La actinoterapia sigue en importancia como causa obstétrica y ginecológica en la determinación de fístulas urogenitales (Everett-124 y Mattingly, Counseller-91 y Haigler, Guixá-161 y Otturi).

Su empleo en la terapéutica de las neoplasias malignas y avanzadas del útero va progresivamente ampliándose. En estos casos la reducción de la indicación quirúrgica se hace, en forma obligatoriá, no por causa de la indicación sino del abuso, al menos prolongado, de la radioterapia, cuya acción necrótica no se limita desafortunadamente a los tejidos alcanzados por el tumor.

Puesto a un lado el factor tocogenético, la cirugía alta y la actinoterapia intensiva representan en verdad las causas directas de la manutención de la ocurrencia de fístulas urogenitales, como entidad importante en los países civilizados.

d) Fistulas por lesiones destructivas de naturaleza inflamatoria y neoplásica. Estas causas también han sido mencionadas. Su incidencia, sin embargo, va declinando, y la tendencia es a desaparecer a medida que se desarrollan los medios de asistencia a la venereología, a la tuberculosis genital, y los de profi-o laxis del cáncer genital.

Las lesiones ulcerosas consecuentes a linfogranulomatosis venérea, a la fusión de gomas sifilíticas, a la tuberculosis genital y a la invasión carcinomatosa del septo uro-genital son las causas que allí se presentan.

e) Fístulas determinadas por otras causas. Son citadas entre otras el uso de "pessarios" (cada vez más raramente), el cateterismo vesical intra-parto con presentación insinuada; las heridas determinadas por el coito; masturbación; prácticas abortivas y substancias antisépticas - permanganato de potasio (Steward-37 y Wenser), la rotura de abscesos sub-uretrales y la implantación de cálculos en el cuello vesical (Salgado-363, 1960); las lesiones consecuentes a la infestación por bilharziasis (Mahfouz-241, 1938) y por amebiasis vaginal (Azevedo-11, 1944); la mortificación de tejidos por estrangulamiento en prolapsos genitales y por la distermocoagulación de lesiones vesicales, y finalmente las lesiones del septo urogenital determinadas por accidentes y fracturas de la pelvis.

\section{VARIEDAD DE FISTULAS URO-GENITALES}

Las lesiones del tracto urinario que, comunicándose con la vía genital, constituyen las fístulas urogenitales, se asientan en la vejiga y el uréter.

De acuerdo con la localización y extensión de estas soluciones de continuidad de las vía urinarias en función de los órganos aicanzados en la comunicación que se establece con el tracto genital, tendríamos las siguientes variedades de fístulas: vésico-vaginales, vésico-uretro-vaginales, vésico-cérvico-vaginales, vésico-cervicales, vésico-uterinas (corporales), vésico-urétero-vaginales, uretro-vaginales, y urétero-vaginales. 
Sería innecesario, en un relato como éste, especificar las situaciones anatómicas de cada uno de estos tipos de fístulas. Sin embargo, vale la pena declarar que las lesiones que comunican la vejiga y uretra con la vagina son las que más se encuentran entre las fístulas tocogenéticas, mientras que las lesiones ureterales aparecen en forma particular, después de amplias intervenciones uroginecológicas.

Cuando el factor tocogenético por compresión (necrosis isquémica) está en juego, son los tejidos vesicales, uretrales y vaginales (por su situación entre los huesos de la pelvis y la presentación fetal) los que sufren mortificación. El uréter, debido a las condiciones especiales durante la gestación se disloca fácilmente, huyendo así de cualquier compresión.

Por otro lado, durante la cirugía ginecológica, las lesiones directas del uréter pueden pasar desapercibidas, mientras que las de la vejiga y uretra son fácilmente individualizadas y reparadas con éxito por el cirujano (Everett-123 y Mattingly).

Además, en la terapéutica quirúrgica de las neoplasias benignas y malignas del útero, el uréter, por su topografía, inervación y vascularización, está más sujeto a las lesiones inadvertidas y a alteraciones de su circulación y trofismo. De ahí la importancia del factor necrosis isquémica en la etiopatogenia de las fístulas ureterales consecuentes a la cirugía radical del $\mathrm{Ca}$ del útero.

Las fístulas ureterales pueden ser en esta forma, uni y bilaterales, y con relación a su topografía y en función de su terapéutica deben ser divididas en bajas (hasta $5 \mathrm{cms}$. de la vejiga), y altas $(5 \mathrm{~cm}$. por encima de la vejiga).

Con relación a la asociación de lesiones, las fístulas urogenitales pueden ser simples y complicadas. En las primeras, por lo general, sori pequeñas, presentan bordes regulares y provienen de causas relacionadas con lesiones quirúrgicas. En las variedades complicadas, la necrosis isquémica está presente por lo general, y en este caso son comunes las estenosis cicatriciales, fibrosis de los tejidos peri-fistulares, las adherencias de la fístula al pubis o a las ramas isquiopubianas, la destrucción total o parcial de la uretra, la duplicidad de orificios fistulosos, las lesiones asociadas del recto, vejiga y uréter $y$, finalmente, cuando la fístula vésico-vaginal o vésico-uretrovaginal es muy amplia, el prolapso o eversión de la vejiga.

Las fístulas vésico-vaginales pueden aún ser clasificadas en pequeñas, medias y grandes; en fijas y móviles, y en función de su accesibilidad, en fístulas a.ltas, medias y bajas. Aquéllas, las altas, en general son originadas por lesiones vesicales directas o indirectas en el curso de una cesárea, y de las histerectomías totales por vía abdominal.

\section{SINTOMAS Y DIAGNOSTICO}

No todos los tipos de fístulas urogenitales están acompañadas del síntoma clásico que las caracteriza: la incontinencia urinaria. Este es el caso de la fístula uretral situada abajo del cuello vesical. Sin embargo, cuando este mismo tipo de lesión se localiza en las cercanías del cuello vesical, el mecanismo 
de su cierre, en virtud de la fibrosis peri-fistular, puede perturbarse y de allí sobreviene la incontinencia urinaria de esfuerzo o no.

En todas las otras variedades hay pérdida involuntaria constante o intermitente de orina por la vagina y vulva, desapareciendo más o menos completamente la voluntad a la micción. El deplorable cuadro clínico psíquico y somático que proviene de esto fue magistralmente presentado por Stoeckel-384, y merecería, como homenaje a este grande ginecólogo, su integral transcripción en este relato, si no fuera por la exigüidad de espacio de que disponemos.

El diagnóstico de la afección se fundamentará en la anamnesis y en los exámenes ginecológico y urológico de las pacientes. De esta forma la necesidad tantas veces referida por Stoeckel-383; Everett-121; Te Linde-391-392; Wharton-420 y Medina-267, de tener el ginecólogo encargado de estas pacientes conocimientos razonables de urología, para que a él no se le escapen pormenores que tienen importancia decisiva para establecer el diagnóstico, el pronóstico y la mejor terapéutica en cada caso.

b) Examen ginecológico. Por el tacto y por el examen con speculum se aprecia la localización, dimensiones, relaciones con órganos vecinos y el estado de los tejidos en el trayecto fistular. Moir-292 recomienda el examen bajo narcosis, que en los casos de difícil acceso es fundamental para la perfecta identificación de la lesión.

La posición de la paciente puede favorecer los indicios del examen de speculum. Para esto se recomiendan las posiciones genu-pectoral de Sims y de Nozeman (o de oración mahometana), elevándose la pared vaginal posterior con ayuda de una valva de Sims. No obstante ser muy incómoda, esta última es la posición que mejor muestra la pared vaginal anterior, sede del orificio fistular. Cuando el examen se alarga, y para evitar las molestias que esta posición determina, nos servimos de la posición ginecológica dorso-sacra, con cefalodeclive (posición de Trendelenburg) de $30^{\circ}$.

Cuando todavía persisten las dudas, recurrimos a las pruebas de cateterización y de replesión vesical, con líquidos coloreados (azul de metileno o leche esterilizada).

Esta última prueba es particularmente útil para identificar la zona vaginal del flujo urinario de las fístulas vésicovaginales. Para excluír este tipo de fístulas y diagnosticar la insuficiencia urinaria de esfuerzo o por insuficiencia esfinteriana (escape de orina entre el catéter y la luz de la uretra), para confirmar la sospecha de fístula uretral (cuando por la vagina no fluye el líquido coloreado, pero persiste su inundación por goteo urinario uretral), para apreciar la existencia de fístula vésicocervical (escape de orina coloreada por el cérvix), y aun para excluír la posible existencia de fístula vesical capilar.

En esta última eventualidad, el llenado vesical con la solución coloreada no siempre se sigue de su escape por la vagina. Taponándose el canal vaginal con varias gasas y haciéndose la paciente caminar, la retirada de las ga- 
sas diferenciará la fístula vésico-vaginal capilar (solamente la gasa situada profundamente en la vagina estará manchada) de la insuficiencia del esfínter vesical (solamente la gasa superficial estará manchada).

En determinados casos de fístulas vésico-cervicales la prueba de replesión vesical no siempre se sigue de salida de orina por el orificio cervical. En algunos casos el canal fistuloso, estrecho, presenta pliegues o, con ocasión de llenado de la vejiga, provoca la obliteración de la fístula por el pliegue polipoideo de la mucosa vesical. El acto de pinzar el cuello y su movilización, bajo tracción, deshace el pliegue o el cierre valvular, a lo que se sigue entonces el chorro del líquido coloreado por el canal cervical.

c) Examen urológico. Para la debida apreciación de las fístulas urogenitales se impone, como complemento, el examen que encuentra en la cistoscopia su principal indicación. Bien ejecutada, ella nos informa sobre la morfología, localización y relación del orificio fistuloso con los ostium uretrales. Aporta aún esclarecimiento sobre la existencia de cálculos e incrustaciones calcáreas, sobre el estado de salud de la mucosa vesical y sobre la existencia de fístula uretral uni o bilateral.

Cuando hay dificultad en localizar los orificios uretrales, la mayoría de los autores (Azevedo-11; Burgos-59; Souza Rudge-352) recomiendan la prueba del índigo-carmín, la cual también informará sobre la función de los riñones y de las vías urinarias superiores.
Azevedo-11 dice que por la uretrocistoscopia es común encontrarse el orificio fistuloso vesical mucho más grande que el existente en la vagina, porque, teniendo la pared de ésta mayor capacidad de retracción, el trayecto fistular se hace infundibuliforme.

Las dificultades relacionadas con la práctica de la cistoscopia deben ser consideradas. Sin embargo, no serán tratadas en ese relato.

En el caso de fístulas ureterales, se debe también echar mano de la pielografía que, además de localizar el uréter lesionado, nos da cuenta de las condiciones del tránsito urinario de uréter contra-lateral, de la función secretora de los riñones y de la posible existencia de uréter supernumerario (Burgos-59).

\section{PROFILAXIS.}

El perfecto conocimiento de las causas etiopatogénicas relacionadas con las fístulas urogenitales constituye el fundamento para su profilaxis. En esas condiciones, debemos considerar, por separado, las fístulas tocogenéticas de aquellas que sobrevienen de cirugía ginecológica y actinoterapia.

En los centros civilizados la mejor asistencia obstétrica redujo hasta casi la anulación la incidencia de fístulas urogenitales tocogenéticas. Para eso han contribuído la mejor apreciación clínica y radiológica del canal del parto, la reducción de las indicaciones de intervenciones como las aplicaciones de fórceps alto y medio, la sinfisiotomía, las versiones internas, las extracciones pélvicas $\mathrm{y}$, principalmente, la liberalidad 
de las indicaciones de cesárea en los casos de parto prolongado. En esta última operación se debe evitar la incisión segmentaria longitudinal, las suturas en masa del miometrio y la disección excesiva de la vejiga.

De hecho tenemos que en los países de bajo índice demográfico y de gran extensión territorial en que la incidencia de fístulas tocogenéticas por necrosis persiste como principal causa de esta entidad clínica, el problema es más complejo; la profilaxis deberá fundamentarse en medidas socio-económicas que vengan a ampliar los medios de comunicación y de educación y que orienten una mejor distribución de los recursos de asistencia médica en cada nación.

La profilaxis de las fístulas uretrales y vesicales en el curso de intervenciones vaginales para el tratamiento del prolapso, se fundamenta en la menor profundidad de la incisión de la pared vaginal anterior. De esta forma, el plano de clivaje obtenido se distanciará suficientemente de la uretra y vejiga, preservándolas de cualquier lesión por sección o necrótica.

En las histerectomías totales, para el tratamiento de ginecopatías benignas, la profilaxis de lesiones uretrales y vesicales encuentra apoyo en el perfecto conocimiento de la anatomía regional, en la disección cuidadosa de la vejiga $\mathrm{y}$ del pedículo uterino (con lo que identificamos los vasos uterinos y el uréter), en la corrección perfecta de las lesiones vesicales que puedan ocurrir y en el drenaje permanente de la vejiga (3-7 días).
El problema se complica, sin embargo, cuando consideramos la profilaxis de las fístulas urogenitales determinadas por la actinoterapia y por la cirugía radical, empleadas en el tratamiento del cáncer uterino. Eso porque, presente la neoplasia maligna, las condiciones aconsejadas para mejorar los resultados (actinoterapia intensa y profunda y extirpación quirúrgica amplia y radical), son exactamente aquellas que responden por el incremento de las fístulas urogenitales en los medios civilizados.

A pesar del perfecto funcionamiento anatómico de la región y de los puntos en que la lesión del uréter, según Rusch356 y Hager, es más común (cruce con los vasos ilíacos, porción intraligamentaria, cruce de la arteria uterina y porción intra-mural), de la técnica operatoria consciente, de la manutención del uréter en la cavidad peritoneal (Novak307), del envolvimiento del uréter con retazos de fascia lata (Dreicon-112), del uso de la urografía excretora pre-operatoria, del cateterismo previo de los uréteres (Rosenfeld-349 y Bergman), y del constante recuerdo de su posible lesión, el accidente se establece, como ya hemos visto, en la frecuencia de 10-11\% en los casos de cirugía radical.

Por otro lado, como en el tratamiento de la neoplasia maligna, la restricción en la amplitud de las resecciones quirúrgicas, implica la extensión de la actinoterapia (Kottmeier-214 y Meigs269 ), el problema permanece insoluble. Por esto, afirmamos que la principal medida profiláctica de las fístulas urogenitales, en medios civilizados, se confunde con aquellas que han sido pre- 
conizadas para la profilaxis y el diagnóstico precoz del carcinoma uterino.

Hay todavía que señalar como medida profiláctica de grande importancia el perfecto acoplamiento de los conocimientos urogin ¿ológicos, indispensables a todo profesional que se preocupa por el tratamiento quirúrgico del $\mathrm{Ca}$ del útero. Con tales atributos, le será más fácil evitar las lesiones del tracto urinario (ligaduras, distorsiones, sección parcial o total, desgarramiento y resección de segmentos de uréter y lesiones vesicales), y una vez identificados, proceder a su corrección quirúrgica durante el propio acto operatorio. Uno de nosotros ( $\mathrm{J}$. R. A.-18), recientemente se ocupó de esta cuestión, recomendando el uso del cateterismo con tubo en $\mathrm{T}$ en los casos de lesiones por ligaduras y sección parcial del uréter, la retirada de puntos en las distorsiones, la uretrocistoneostomía (lesión baja) y la anastomosis términoterminal (lesión alta), en los casos de sección completa y pequeñas resecciones del uréter.

En las resecciones extensas de segmentos del uréter la mejor conducta estaría en la ureterostomía cutánea provisional.

Finalmente, atendiendo a los buenos resultados que uno de nosotros (J. R. A.-18) ha obtenido con la urétero-ileocistoplastia en la corrección de lesión bilateral de los uréteres, pensamos que en determinados casos de $\mathrm{Ca}$ del cuello del útero, sería conveniente realizarla como medida profiláctica, sustituyéndose los uréteres pélvicos ya en el acto operatorio, por una asa aislada del íleo terminal, que es anastomosada a la vejiga. En esta forma, se podría practicar la exéresis amplia de la pelvis y garantizar el perfecto funcionamiento del tracto urinario.

\section{TRATAMIENTO DE LAS FISTULAS UROGENITALES}

Capítulo complejo porque además de las numerosas técnicas sugeridas para el tratamiento quirúrgico de cada variedad de lesión, importa recordar que los principios generales que presiden la terapéutica quirúrgica de las fístulas ureterales son distintos de aquellos que se aplican en las vesicales y uretrales.

Consideramos las siguientes cuestiones: 1 a Operabilidad; 2 a Pre-operatorio; 3a Cirugía de las fístulas vesicales y uretrales; 4 a Cirugía de las fístulas ureterales; 5 a Cirugía de los casos "incurables", y 6? Post-operatorio.

1. Operabilidad. La revisión histórica del tratamiento de estas lesiones demuestra que si por mucho tiempo fueron tenidas como incurables (Moir292), hoy, gracias a los avances de la técnica de la anestesiología y de la prevención de la infección, "prácticamente todos los casos son operables". Sin embargo, esta afirmación arrojada pero comprensible porque partió de la grande experiencia de Clovis Salgado-393, merece el reparo de Fritsch-145 (1899), que a su tiempo ya preconizaba al afirmar que "existen centenares de operadores de fístula, pero solamente muy pocos llegaron a acumular la experiencia indispensable".

Frente al grave sufrimiento físico y moral que la enfermedad determina, las 
pacientes se someten con facilidad a la idea de la necesidad de repetir las intervenciones tantas veces cuantas sean necesarias. Empero, antes de practicar cualquier operación, fíjese en la posibilidad de la "cura espontánea" o el tratamiento por la simple electrocoagulación de sus bordes.

La tendencia a la cura espontánea es mayor en las lesiones obstétricas que en las ginecológicas, ocurriendo con mayor posibilidad en las fístulas de pequenas dimensiones y en la variedad vésicocervical.

Se puede contar con esta solución solamente dentro de los tres primeros meses de la instalación de la fístula y mientras sus bordes están granulando. Según Stoeckel-384, la favorecen el combate a la infección y el sondeo permanente de la vejiga.

La llamada "cura espontánea" de la fístula ureteral, cuya frecuencia, según Carter-66, sería de 50\%, no tiene el mismo sentido clínico que caracteriza la cura de las fístulas vesicales y uretrales. Mientras en éstas la desaparición de la incontinencia urinaria representa solución satisfactoria y feliz, en aquellas, la continencia urinaria traduce la estenosis de la luz ureteral, por fibrosis peri-fistular y determina, como consecuencia, la hidronefrosis y la pérdida definitiva de la función renal.

En los casos de fístula vesical muy pequeña, cuando después de los tres meses de expectativa, no ocurrió la cura espontánea Ottow-311, Martius-255 y particularmente Falk-127, emplearon con éxito la electrocoagulación intravesical de sus bordes $\mathrm{y}$, entre nosotros,
Fabiao-126, utilizó la cauterización con solución de nitrato de plata al $15 \%$. Moir-292 contraindica este método, porque en los casos en que lo utilizó, el trayecto fistuloso se agravó.

Hay fístulas cuyo tratamiento quirúrgico es dispensable. Así, las fístulas uretrales bajas, que por su localización no condicionan incontinencia $\mathrm{u}$ otros síntomas desagradables. Por otro lado, hay fístulas en que las condiciones locales agravadas por la repercusión del estado general, hacen temeraria e infructiva cualquier tentativa quirúrgica. Son los llamados "casos incurables".

Afortunadamente su número no es grande y al revisar casuísticas numerosas de servicios dirigidos por profesores experimentados en este tipo de cirugía, se verifica que fueron del orden en 3.6\% (entre 602 casos para Lucas Machado-238; en $9.8 \%$ (en 122 casos) para Souza Rudge-352; en $0.5 \%$ (entre 190 casos) para Clovis Salgado-363; en $11.5 \%$ (entre 253 casos) para Counseller-91 y Haigler; en $2.0 \%$ (entre 149 casos) para Everett-124 y Mattingly; en $0.8 \%$ (en 230 casos) para Moir-292, $\mathrm{y}$, finalmente, en $1 \%$ (en 244 casos) para Peltier de Queiroz-333a.

Mahfouz-239, cuya gran habilidad lo acredita entre los especialistas de mayor experiencia en este tipo de cirugía, consideraba incurables las fístulas en las cuales la uretra y el esfínter están totalmente destruídos y los casos en los cuales la pared vesical remanente es insuficiente para formar una vejiga de buena capacidad. En estas eventualidades, la operación está destinada a ser un fracaso porque en el primer caso per- 
siste la incontinencia, y en el segundo, la orina es expelida con mucha frecuencia. Así, aun cuando técnicamente la operación sea de éxito, desde el punto de vista del paciente no se comprobó mejoría.

Una serie de innovaciones técnicas mejorarán suficientemente los resultados relacionados a las fístulas vésicouretro-vaginales, con destrucción del esfínter. Sin embargo, según Souza Rudge-354 y otros, es de ellas de donde derivan la mayor parte de los casos incurables. Para este autor las fístulas urogenitales incurables comprenden dos grupos bien definidos: en el primero se incluyen los casos en que la existencia de extensa fibrosis cicatricial producida por la necrosis y por la pericistitis, determinó gran reducción de la capacidad del reservorio urinario y la transformación de los tejidos pélvicos en material impropio para la sutura; en el segundo, están las fístulas que recidivan a diversas operaciones y en las cuales las condiciones locales empeoran a cada intervención, para, finalmente, asemejarse a las del primer grupo. Las fístulas obstétricas, por necrosis, por la fibrosis cicatricial perifistular, por la pericistitis, por la fijación ósea y destrucción del piso vesical de la uretra y del esfínter vesical, son las que más frecuentemente se incluyen en la categoría de incurables.

En lo que respecta a las fístulas ureterales, son las lesiones altas del uréter o la pérdida de su segmento pélvico, los factores de mayor gravedad. En estos casos la pequeña posibilidad de restablecerse con éxito funcional la continuidad del tracto urinario, justifica la indicación de la nefrectomía cuando el riñón contralateral es normal. Como se ve, el criterio de incurabilidad es más sencillo en los casos de lesiones ureterales.

La primera intervención, en caso de fístula vesical o uretral, no debe ser hecha antes de transcurrir dos o tres meses del accidente causal. En el caso de operaciones iterativas, a fin de evitar los inconvenientes originados de la tensión y fibrosis de los tejidos, se recomienda también intervalos de dos a tres meses entre las intervenciones operatorias.

Collins-81-82 y Cols. recomiendan el uso de la cortisona asociada a la penicilina en el sentido de reducir este tiempo de espera. En un sentido opuesto y contrariamente el pensamiento de Meigs-268, que recomienda 8 a 10 meses para intervenir, juzgamos que la operación para el tratamiento de la fístula uretral debe ser precoz (30-40 días después del diagnóstico) a fin de reducir el riesgo de infección urinaria ascendente y de perturbaciones más o menos graves de la función renal.

2. Pre-operatorio. Es de grande influencia para el éxito del tratamiento quirúrgico de las fístulas y comprende cuidados generales y locales.

a) Cuidados generales. En las pacientes portadoras de fístula tocogenética, son comunes los estados de anemia, avitaminosis, afecciones asociadas (la lúes y la verminosis estuvieron presentes, respectivamente, en $39.5 \%$ y 48.4\% en el material de Azevedo-11) y principalmente la mala cicatrización que los caracteriza. Su corrección es im- 
periosa, así como lo son las medidas psicoterápicas, con la finalidad de elevar el estado psíquico, tan miserablemente agravado en estos casos.

El uso de antibióticos y quimioterápicos (antecedido de cultivo de orina y antibiograma) y de medidas alcalinizantes del flujo urinario (dieta rica en proteínas y pobre en frutas y legumbres, ácido mandélico, cloruro de amonio, urotropina y benzoato de sodio), nunca debe ser descuidado.

En los casos considerados "incurables" y en los cuales se optó por la urétero-anastomosis intestinal, los trabajos experimentales de Barelare-29 y Vest, confirmados en la clínica por Higgins-169, Lower-227; Wharton-420; Azevedo-11 y Souza Rudge-354, justifican para la antisepsia del tracto intestinal el uso liberal del succinil-sulfatiazol, por vía oral, 7 a 10 días antes de la operación.

b) Medidas locales. Las informaciones obtenidas por los exámenes ginecológico y urológico son indispensables (Falk-127) para la apreciación del caso y para la correcta indicación quirúrgica.

La mejoría de las condiciones locales (maceración e infección de la mucosa vulvo-vaginal y de la epidermis de la región peri-vulvar), por la aplicación tópica del aluminio metálico, bajo forma de pasta, ha sido muy útil, según la experiencia de nuestro Servicio. Cuando esta medida no fuere suficiente, se recomienda la derivación urinaria, temporaria, por medio de sonda de Foley, que emergiendo del orificio fistuloso (fístulas vesicales) o del meato urinario uretral (fístulas uretrales) favorece la reepitelización local.

3. Tratamiento quirúrgico de las fístulas vesicales y uretrales. Consideraremos:

a) Vías de acceso; b) Posición del paciente; c) Anestesia; d) Material; principios generales, y f) Técnicas operatorias.

a) Vías de acceso. La vía vaginal es aún la escogida. En los casos de fístulas altas o de vaginas muy estrechas, por estenosis cicatricial o no, la incisión para-vaginal de Schuchart-Schauta favorece el acceso al campo operatorio. Las fístulas de la cúpula de la vejiga, consecuentes por regla a las histerectomías abdominales y a la operación cesárea, son de acceso más fácil o apenas posible, por la vía supra-púbica (operación trans-abdominal y trans-vesical). Moir-292, en 230 intervenciones la utilizó en solamente 2\%, y Clovis Salgado363 , la asoció a la vía vaginal exclusivamente en $1 \%$ de sus 177 casos, y Peltier de Queiroz-333 en principio no la recomienda. Sin embargo, se verifica la tendencia para la ampliación de sus indicaciones. Ahumada-3 y Calandra (1953), al revisar la bibliografía han encontrado 261 casos de operaciones trans-vesicales (operación de Trendelenburg) con $93 \%$ de curas. Refieren aún que la mayor experiencia es la de Marion, quien operó 50 pacientes, con éxito 48 de ellas. Phaneuf327 y Graves la utilizaron 40 veces, obteniendo buen resultado en 39 casos, y Thouvenot-398 y Marneffe (1957) y Machado-238 (1961) resultan sus méritos. 
b) Posición del paciente. Al favorecer una buena exposición, hace el éxito operatorio más probable. Fue justamente por la mejor visibilidad en examen de paciente portadora de fístula, en la posición que tomó su nombre por lo que Sims-292 se convenció de la curabilidad de la afección tenida hasta entonces como definitiva.

Aun cuando algunos cirujanos todavía insistan en el uso de la posición genupectoral (Russell-357 y Miller-277 y Fernández-133), la verdad es que las facilidades que advinieron de la buena anestesia y de la ampliación de la abertura vulvar, la hicieron prácticamente innecesaria y hasta desventajosa por el acúmulo de sangre al nivel del campo operatorio y por la falta de comodidad.

Hoy en día utilizamos la posición ginecológica clásica, acrecida de la elevación del sacro y fuerte flexión y abducción de los miembros inferiores. Se disminuye en esta forma la lordosis lumbar, y la pared vaginal anterior, zona de la lesión fistulosa, se presenta dirigida en un sentido vertical y fácilmente accesible.

La posición genu-pectoral de Sims sería excepcionalmente indicada en los casos en que la fístula, por fenómenos de retracción, se localizara en la cara posterior del pubis (Moir-292).

c) Anestesia. La intervención para el tratamiento quirúrgico de las fístulas urogenitales debe ser hecha con mucho cuidado. "El cirujano que tenga mucho afán, no la debe realizar", Moir-292.

De allí la necesidad del método anestésico que, al lado de buenas condiciones de operabilidad, proporcione actua- ción duradera y atóxica. El bloqueo anestésico sub-aracnoideo o peridural, atendiendo a estas exigencias, ha sido la anestesia de elección en el Servicio en que trabajamos y en otros centros de Brasil (Salgado-363; Azevedo-11; Lucas Machado-236; Fernández-134 y Sa Leitao y Peltier de Queiroz-333a).

d) Material. Aun cuando algunos autores de renombre (Doderlein-109 y Kronig; Stoeckel-383 y Salgado-363), dispensaron el uso de material apropiado, Azevedo-11; Lucas Machado-236; Rudge-352, Falk-127, Burgos-59; Werneck-416; Te Linde-390 y principalmente Moir-292, resaltan el mérito de la valva de Sims, de pinzas, bisturís, porta-agujas y tijeras de mango largo y extremidad curva, de aguja atraumática con curvatura en forma de anzuelo, de aspiradores, jeringa de Dakin y, finalmente, del aparato de iluminación para uso céfalo-frontal. Para Salgado363 tales instrumentos pueden ser dispensados siempre que el ginecólogo se sirva del desbridamiento vulvo-vaginal que favorece el acceso al campo operatorio.

El tipo de hilo utilizado para la sutura no es uniforme. Para el cierre de la vejiga, la preferencia es para los hilos de catgut simples (Burgos-59; Salgado363; Souza Rudge-352) o cromados, 1, 0, 00 y 000 (Moir-292; Azevedo-11; Lucas- Machado-236; Doderlein-109 у Kronig; Phaneuf-324; Mahfouz-241 у Couri-92). Para la sutura vaginal, mientras algunos utilizan el mismo tipo de hilo usado en el cierre vesical (Lucas Machado-236, Salgado-363, Souza Rudge-352, Döderlein-109, y Kronig, Martius-225, Rawls-336, Crossen-98 y Cro- 
ssen, Duncan-113, Fernandes-134 y Sá Leitã $O$ ), otros usan el catgut simple (Azevedo-11 y Burgos-59), o cromado (Franz-140 y Döderlein-109 y Kronig), o aun el hilo de nylon (Moir-292) y los de seda (Simon-352 y Peham-319 y Amreich).

Los hilos metálicos y los hilos de material no-absorbible (seda, nylon, crin, algodón, etc.), no se justifican porque, como ya lo demostrara Simón-352, ellos cortan el tejido al fin de 72 horas. Por eso proferimos el cat-gut cromado, que no tiene este inconveniente $\mathrm{y}$, exigiendo mayor tiempo para su re-absorción que el hilo simple, representa el hilo de elección para las suturas vesicales (No 00) $y$ de la vagina ( $N$ : 0 o 00$)$.

e) Normas generales. Excluyendo las experiencias aisladas que pueden sugerir conclusiones equivocadas, los grandes centros de tratamiento de fístula llegaron de modo aislado a varias conclusiones idénticas. Atendiendo a la experiencia de nuestro Servicio y a la experiencia de Lucas Machado-236, Peltier de Queiroz-333a, Clovis Salgado-363, Rudge-352, Burgos-59, Martiniano Fernandes-133, Azevedo-11, Mahfouz-243, Moir-292, Phaneuf-325, y Stoeckel-383, que en este particular nunca sería por demás apreciada, recomendamos para el tratamiento quirúrgico de las fístulas urogenitales las siguientes normas generales: 1. Examen local cuidadoso (por el propio cirujano) y, si necesario, bajo narcosis a fin de identificar el trayecto fistuloso, los órganos y estructuras vecinas, la elasticidad y movibilidad de las zonas perifistulares, la irrigación local y la presencia de infección e incrusta- ciones calcáreas en la vejiga y en la vagina.

2. Aplazar la intervención hasta que el estado general (anemia, hipoproteinemia, etc.), y las condiciones locales (principalmente la infección), estén corregidas.

3. Preferir la vía vaginal, en la posición ginecológica modificada (hiperflexión y abducción de los miembros inferiores acrecida de la elevación del sacro o de ligero céfalo-declive).

4. Obtener buena exposición del campo operatorio, haciendo uso para cuando sea necesario, del desbridamiento vulvo-vaginal de Schuchart-Schauta y de incisiones eventuales bridas cicatriciales.

5. Proceder a la exposición de la fístula por el método de desdoblamiento, disecándose ampliamente la vejiga de la vagina $\mathrm{y}$, particularmente, a costa del retazo vaginal.

6. Cierre de la vejiga con puntos separados, de cat-gut cromado 00 o 000 cogiendo el tejido sub-mucoso vesical, sin penetrar en la cavidad.

La línea de sutura, atendiendo a la dirección de la fístula, será orientada en forma de no forzar el retazo. En el caso de alguna tensión se debe ampliar el descollamiento en todas las direcciones. Una segunda línea de sutura del plano sub-vesical puede ocasionalmente ser hecha cuando el estado local (ausencia de tensión) lo permita.

7. La prueba de replesión vesical se realiza por la introducción de leche estéril o de solución de azul de metileno, 
antes de proceder a la sutura de la pared vaginal.

8. Cierre del retazo vaginal con puntos separados de cat-gut cromado No 0 o 00. Este plano de sutura, cuando es posible, debe cruzar perpendicularmente la línea de sutura sub-vesical. En caso de tensión de los retazos vaginales, practicar las incisiones laterales, que la reducen.

9. Manipuleo delicado de los tejidos peri-fistulares con el fin de evitar alteraciones circulatorias y presencia de coágulos entre los dos planos de sutura.

f) Técnicas operatorias. En nuestro punto de vista, las técnicas a ser utilizadas se reducen a 3 grupos de fístulas: a) La que se aplica en los casos comunes de fístulas vesicales y uretrales; b) Las que se utilizan en los casos de fístulas vésico-uretro-vaginales con comprometimiento del esfínter vesical y aquellas que destruyen prácticamente toda la uretra, y c) Las que se aplican en las fístulas vesicales altas y de acceso impracticable por la vía baja.

Para las primeras, la técnica que merece la aprobación de los grandes estudiosos de la materia (Salgado-363, Souza Rudge-352, Fernandes-133, Azevedo-11, Lucas Machado-236, Burgos-59, Falk-127, Moir-292, Krishman-215, y Counseller-91, y Haigler), es la del "desdoblamiento", descrita en 1861 por Collins en Dublin. Consiste esencialmente en la disección de las paredes vesical y vaginal de modo de poder suturarlas sin tensión y separadamente.

Son numerosas las pequeñas variantes de esta técnica. Simon-352 recomendaba, además del desdoblamiento, el avivamiento (aumentar) o la extirpación del canal fistuloso; Mackenrodt352 dio mayor extensión a la disección vésico-vaginal, al recomendar la movilización amplia de la vejiga; Futh-148 adoptó la incisión circular de la mucosa vaginal a cierta distancia del orificio fistuloso, de forma a invertir un manguito de la mucosa vaginal para el interior de la vejiga; Salgado-236 sugiere la disección vesical hasta la abertura del peritoneo, cuyo labio es traccionado y fijado abajo de la sutura de la vejiga, de "modo de afrontarla y protegerla".

En las fístulas vésico-uretro-vaginales con comprometimiento del aparato de cierre de la vejiga y con destrucción extensa de la uretra, la elección de la técnica exige la presencia de cirujano con grande experiencia. Antes de admitir la incurabilidad y la opción por cleisis vaginal o derivación urinaria, debe el ginecólogo poco experimentado apelar, sin que eso signifique disminución, para él, al auxilio de otros centros donde, por razones varias, la infeliz paciente encontrará en un técnico con mayor conocimiento la solución de su enfermedad.

Cuando el aparato esfintérico vésicouretral es insuficiente por distensión o rotura sub-mucosa (lo que no es raro), los procedimientos adoptados para corregir la fístula y la incontinencia urinaria que podría quedar, a pesar del perfecto cierre del fistuloso, han sido varios. En las lesiones de pequeña extensión, con orificio fistuloso cercano del cuello vesical, la amplia movilización lateral, exponiendo bien los márgenes de la unión uretro-vesical, per- 
mite que los puntos de la segunda sutura, a partir de la uretra y hasta el trígono, saquen los bordes del esfínter uretro-vesical. Es la técnica de Kelly que, en estos casos más fáciles, ofrece éxito y se presenta como el método de elección.

Sin einbargo, si la unión vésico-uretral se presenta total y extensamente destruída, la técnica de Kelly no satisface. En estos casos han sido preconizadas las técnicas de Martius-225 (utilización uni o bilateral del pedículo fibro-grasoso del labio mayor que será "superpuesto" a la línea de sutura vésico-uretral), la plastia piramido-facial de Goebell-Stoeckel (tracción bilateral de pedículos músculo-aponeuróticos piramido-faciales que al cruzar se colocan en anillo bajo la uretra) y las dos intervenciones sugeridas por IngelmanSundberg-183-5 (1) el pedículo del músculo recto anterior del abdomen es traccionado hacia abajo $\mathrm{y}$, atravesando el espacio de Retzius, se colocará bajo la cúpula vaginal; 2. Se separa el músculo gracilis en su extremidad distal y, cogido hacia abajo por el orificio obturador, alcanza la pared vaginal bajo la cual será fijado.

Salgado-363 admite las técnicas de Martius y Goebell-Stoeckel ser válidas solamente para obtener la oclusión del orificio fistuloso pero impropias para promover la continencia uretral. Lucas Machado-238, con amplia experiencia (602 casos de fístulas urogenitales, de las cuales 90 con lesión uretral grave), recomienda la operación de Gray-Ward y la de Ingelman-Sundberg para los casos más graves.
Al no encontrar solución para los casos en que queda la incontinencia urinaria, y fundamentado en su gran experiencia quirúrgica, Salgado-360 sugirió nueva técnica para reconstruír una uretra continente. La llamó "miorrafia sub-uretral de los bulbos cavernosos". En resumen consiste en "alargar la uretra hasta el clítoris y bajo esa neo-uretra, suturar uno al otro, los músculos bulbocavernosos convenientemente movilizados, pero conservando sus inserciones normales. Esta sutura es hecha en la mayor extensión posible, tanto hacia adelante como hacia atrás, en forma de que la nec-uretra quede envuelta por los bulbos cavernosos". Refiere aún que la practicó en 29 casos. El completo éxito ocurrió en $17(58.6 \%)$ y estuvo siempre dependiente de músculos bulbo-cavernosos bien desarrollados. Peltier de Queiroz-333a también utiliza los bulbos cavernosos para este fin.

Ingelman-Sundberg - 183 recomienda su técnica para los casos de fístulas necróticas (isquémicas) por irradiación; Lucas Machado-238 también utiliza de la misma y Moir-292 sostiene que los mejores resultados son obtenidos por la segunda variante (utilización del músculo gracilis).

Bastianse, citado por Moir-292 para el mismo tipo de fístula, sugiere nueva técnica basada en la disección de lecho vesical hasta la abertura peritoneal. Con esto se favorece la movilización y cierre de la vejiga. En seguida, por vía abdominal, libera el pedículo del epiplón cólico, con circulación intacta, poniéndolo entre el lecho de la sutura vesical y la vagina. 
Aun en los casos difíciles, asociados a lesión del recto, Lucas Machado-235 (1944) recomienda y Burgos-59 lo confirma la derivación transitoria de las heces por la colostomía ilíaca izquierda. Corregida la lesión recto-vaginal repara la fístula urogenital en un segundo tiempo, cerrándola o haciendo uso de la derivación urétero-intestinal.

Llegamos por fin al tipo de fístula vesical que, por su inaccesibilidad por vía vaginal, exige la práctica de intervenciones supra-púbicas, extra-peritoneal e intra-vesical (operación de Trendelenburg) o transperitoneal extravesical. Moir-292 prefiere la técnica transperitoneal extravesical, que por la disección de la pared vesical de la cúpula vaginal, permite la sutura en dos planos. Sin embargo, la fibrosis local no siempre permite la separación del septo-vésico-vaginal. En esta eventualidad, se corta (incisión) la vejiga medianamente (técnica intra-vesical) y con ella abierta, se sutura la abertura fistular y, después, la línea de incisión vesical.

Los urólogos y también los ginecólogos adictos a la cirugía urológica, prefieren la vía supra-púbica, la técnica extraperitoneal transvesical (Faik-127, Ahurnada-3 y Calandra, Phaneuf-327 y Graves, y Thouvenot-398, y Marneffe), que, además de proteger los uréteres, favorece el drenaje vesical supra-púbico. Moir-292, a pesar de estas ventajas reales, no la recomienda porque, además de la mayor dificultad técnica, ella condiciona mayor incomodidad para el paciente, y en los casos de falla (insuceso), reduce la posibilidad de nueva cirugía.
4. Cirugía de las fístulas uretrales. Será precedida de examen urológico perfecto a fin de identificar el tipo de lesión (uni o bilateral; completa o parcial; en pico de flauta; su altura, baja o alta) y el estado funcional de los riñones. De allí se deduce ser tales lesiones del ámbito del urólogo o, por lo menos, del ginecólogo-urólogo.

Uno de nosotros (J. R. A.-18) esquematizó la siguiente conducta terapéutica de las fístulas ureterales: En las fístulas parciales, el tratamiento debe consistir en dilataciones ureterales progresivas, según el precepto original de Townsend-399 y en el cateterismo ureteral por dos a tres semanas (Kuss-218).

En las fístulas totales y en aquellas en que el cateterismo dilatador no fue posible y siempre que las pruebas de la función renal se muestren normales, la cirugía debe ser inmediata. Si existe hidronefrosis infectada, la intervención será precedida de la nef́rostomía temporal.

El tipo de operación depende del nivel de la féstula. Cuando baja, se impone la re-implantación del uréter en la vejiga o ureterocistoneostomía. Se prefiere la vía extraperitoneal, que además de favorecer el acceso, reduce el riesgo de infección consecuente al extravasamiento de la orina.

En las fístulas ureterales, después de histerectomía radical y a pesar de la localización baja, las adherencias, la dilatación, la hipotonía y la falta de peristaltismo que caracterizan el uréter pélvico, hacen funcionalmente inútil su reimplantación en la vejiga. En este caso, así como en aquellos en que la 
función del riñón homolateral está destruída, concluímos por la incurabilidad de la lesión, recomendando respectivamente la derivación uréterointestinal y la nefrectomía.

En las fístulas altas, la conducta es más compleja. Eso porque, en las anastomosis término-terminales, no siempre es posible atender a los preceptos de Patton-317 (acercamiento de los cabos sin tensión; reducir la disección a fin de garantizar buena circulación; uso del "splinting" adecuado — catéter ureteral, tubo de polietileno o tubo en t"-, control de la infección y evitar el extravasamiento urinario).

En esta eventualidad, la corrección se hará por las implantaciones indirectas del uréter en la vejiga, haciendo sustituír la porción situada por debajo de la fístula por un retazo vesical, que es canalizado y llevado hasta el uréter (operación de Boari-Ockerland, 1947), o por una aislada del íleo terminal (urétero-íleo-cistoplastia). En esta última operación, ambas extremidades del asa aislada son cerradas, practicándose la anastomosis urétero-intestinal por la técnica de Cordonnier o de Nesbit y, finalmente, practicándose la anastomosis látero-lateral entre el asa y la cúpula de la vejiga.

Aun cuando algunos autores (Kuss218, Burns-60, Conger-83, y Rouse) hayan tenido resultados satisfactorios con la técnica de la canalización del retazo vesical, Moore-295 no la aconseja porque el perjuicio del mecanismo neuro-muscular del uréter lleva a malos resultados finales.
Juntamente con Annis-8, Bitker-38, Couvelaire-94, Davids-104 y Lesnick, Davids-105 y Nealon, Foret-136 y Hangshem, Freitas-56 y Sadi, Goodwin154 y cols., Kusonoki-216-17 y cols., MacDonald-231 y Kataria, Mc Lean266 y Fais, Moore-296 y cols., Ortved310, Pyrah-333 y Rapper, Rack-334, y Ulm-402, somos de opinión de que la urétero-íleo-cistoneostomía es la intervención que mejor atiende y soluciona estos casos clínicos.

5. Cirugía de los casos incurables. Son tres los tipos de operación que han sido empleados en la solución quirúrgica de los casos de fístulas urogenitales incurables: la colpocleisis, la nefrectomía y las derivaciones uréterointestinales.

Colpocleisis. La colpocleisis tiene su indicación limitada a las fístulas vésicovaginales altas, consecuentes por lo general a la histerectomía total, por gi. necopatías benignas en pacientes en plena menopausia. Para Moir-292 esta intervención sería sencilla en principio, pero su ejecución, además de difícil, no siempre tendría éxito.

Los autores americanos del norte (Falk-127 y Holden 180) se refieren a esta intervención, llamándola operación de Latzko. Sin embargo, como resalta Moir-292, no siempre esta última intervención promueve una completa colpocleisis y, por otro lado, su técnica no difiere mucho de la primitiva operación de Sims.

Por colpocleisis deben ser tenidas solamente las intervenciones que cierran el canal vaginal, en zona más o menos 
alta, y que, no cerrando la comunicación fistulosa, mantienen un divertículo entre la vejiga y la vagina. Esta es, en verdad, su mayor inconveniencia y la razón por la cual debe ser abandonada (Machado-236).

Nefrectomía. La indicación de la nefrectomía se reservará para los casos de fístula ureteral, cuando el riñón correspondiente al uréter lesionado presenta capacidad funcional muy baja, con mala concentración, hidronefrosis infectada o pionefrosis y el riñón contralateral está absolutamente normal (Carter-66, Millin-282 y Colby-80). Sin embargo, en la opción a esta actitud, el clínico no debe olvidar: 1. Que el parénquima renal, corregidas las condiciones de obstrucción de la vía excretora, tiene gran capacidad de regeneración; 2. Que en las lesiones ureterales consecuentes a la cirugía radical, para la cura del $\mathrm{Ca}$ del cuello del útero, es muy común el comprometimiento de ambos uréteres, y difícilmente encontramos uno de los riñones en tan buenas condiciones que justifique el sacrificio del otro.

Estas dos restricciones reducen en mucho las indicaciones de la nefrectomía en la solución quirúrgica de las fístulas ureterales altas o consecuentes y las resecciones más o menos extensas de la vía ureteral.

Derivaciones Urétero - intestinales. Hinman-175 y Weyrauch (1937) y después Hinman-171 (1939) y Bohne-41 (1953), agruparon las 79 técnicas de urétero-sigmoidostomías hasta entonces descritas, de acuerdo con los 11 principios fundamentales a los cuales las mismas obedecían. De éstas merecen citación y tienen aplicación clínica solamente las de Coffey I y II-73-5 (190931), Nesbit-304, Cordonnier-84 (1949) Leedbetter-222 (1951) y las de Mathisen-258 (1953), y de Goodwin-164 y cols. (1953).

Tal afirmación se fundamenta en los datos comparativos y experimentales de Riba-343, Woodruff-426 y cols., Weyrauch-419 y Young, Maluf-245, Dempster-106 y Daniel, y uno de nosotros (J. R. A.-17) practicando urétero-sigmoidostomías en perros y verificando la incidencia de la obstrucción o estenosis de la boca anastomótica, el reflujo y extravasamiento de material contenido en el segmento intestinal y la infección ascendente que se siguen a las intervenciones. Por otro lado, la observación clínica inmediata y tardía de las pacientes sometidas a urétero-sigmoidostomías por las técnicas de Coffey (Mayo-260261, Mayo 263 y Walters, Mayo 262 y Hendricks, Hinman-172, Higgins-168 y 170, Cabut-61-62, MacComb-265, Lower-226 y 227, Priestley-330 y Strom, Hess-166, Marshall-252 y Gardner, Marshall-251, Gouverneur-159 y Aboulker, Hellstrom-165 y Romanus, Millin282, Riches-345, Jacobs-188, Gouvea158, Rudge-354 e Itibere-187), por las técnicas de Cordonnier-Nesbit (Hinman Jr.-175, Cordonnier-87 y Lage, Freire-141 y Almeida, Pacheco-314, Darget-103 y Ballanger), y por la técnica de Leadbetter (Leadbetter-223 y Clarke, Clarke-72 y Leadbetter y Bourque-46) también confirma nuestro punto de vista, según el cual serían estas las técnicas aconsejadas en la práctica de las urétero-sigmoidostomías. 
Cupo a Coffey-73 (1909) la gloria de haber sistematizado y practicado en perros las derivaciones ureterointestinales, que por sus resultados, abrieron nuevas perspectivas en este tipo de cirugía. Su técnica (Coffey-I) consistía en la implantación de 2 a $3 \mathrm{~cm}$. de la extremidad distal del uréter entre las túnicas mucosa y muscular de la pared intestinal; el segmento ureteral anastomosado permanecía cerrado por la presión ejercida por el contenido fecal y por los gases intestinales, abriéndose solamente por acción del peristaltismo ureteral para dar paso a la eyaculación urinaria.

La infección ureteral ascendente y el perjuicio de la excreción urinaria, que explican la elevada mortalidad consecuente a esta técnica, sugirieron a Coffey-75 (1925) el uso de catéteres (Coffey-II). De esta forma se permitió la transplantación simultánea de los uréteres, sin riesgos de obstrucción consecuente al edema post-operatorio, de la mucosa ureteral, en la zona de implantación.

Algunos hechos observados a seguir, justificaron la reserva de los especialistas con relación a las técnicas de Coffey. Así los trabajos experimentales y clínicos de Higgins-167 (1937) demostraron que el túnel sub-mucoso (según la técnica de Coffey), ofrecía adecuado mecanismo valvular, pero el edema y la infección de la porción intra-luminar del uréter determinan obstrucción y consecuente dilatación del tracto urinario superior. Por otro lado, Hinman174 y Weyrauch (1942) estudiando la porción libre del uréter implantado, demostraron su necrosis anémica y consecuente eliminación, formándose al nivel de la desembocadura del uréter, en el intestino, una zona de fibrosis acrecida de la infección local que explicaría la obstrucción de la vía urinaria.

En 1949, Cordonnier-84 y Nesbit-304, trabajando por separado y enterados de los inconvenientes relacionados a la presencia de porción intra-lumbar del uréter, en la luz intestinal, sugirieron la anastomosis directa, mucosa a mucosa, entre el uréter y el intestino, según la sugerencia anterior de Smith-Chaput (1892) y Peterson (1901), citados por Hinman-173 y Weyrauch. En la técnica de Cordonnier, el uréter es seccionado en el sentido transverso, mientras en la de Nesbit, la extremidad de la sección es preparada en espátula o raqueta (anastomosis elíptica), de modo a favorecer boca anastomótica más amplia y reducir el riesgo de la estenosis cicatricial.

Estas dos nuevas técnicas, ventajosas con relación a la de Coffey, en lo que se relaciona a la obstrucción uretérica, ampliaron sin embargo las posibilidades del reflujo y extravasamiento urinario, según se verificó clínica y experimentalmente (Baker-22 y Miller, y Whisenand-422, y Moore).

Leadbetter-222 (1951), considerando las ventajas y desventajas de las técnicas de Cordonnier y Nesbit, propuso la técnica que llamó de "combinada". Asoció la anastomosis directa mucosa a mucosa, al túnel sub-mucoso de Coffey. Aconsejando altos niveles para la anastomosis, implanta primeramente el uréter (a la altura de la unión del sigmoide con el colon descendente, en la cinta inferior y, después, el D. (en la inicia- 
ción de la porción descendente del sigmoide).

Una serie de trabajos experimentales y clínicos (Riba-343, Woodruff-426 y cols., Weyrauch-419 y Young, Dempster-106 y Daniel, Leadbetter-223 y Clarke, Clarke-72 y Leadbetter, Bourque y uno de nosotros J. R. A.-17), han confirmado definitivamente los méritos de la intervención propuesta por Leadbetter, siendo actualmente la técnica que se ejecuta en los Servicios de urología y ginecología de la Facultad de Medicina de la U. S. P.

Finalmente, las técnicas de Mathisen258 y la de Goodwin-154 y cols. (anastomosis uréterointestinal transcólica a cielo abierto), desde 1953 no han sufrido aún suficiente sanción clínica y experimental que justifiquen su uso más liberal.

A partir de 1927 y hasta 1949, varios autores (Bollman-43 y Man, Boyd49, Jewett-193 y 194 y Sauer-369), analizaron o se refirieron a las perturbaciones de la nitrogenemia, de la reserva alcalina y de la función renal en los post-operatorios de derivaciones uréterointestinales.

Examinando 112 pacientes sometidas a la urétero-sigmoidostomía bilateral, Ferris-135 y Odel (1950) llamaron la atención para las alteraciones metabólicas (elevación del cloro sanguíneo, baja de la reserva alcalina y aumento de urea) que se siguieron independientemente de la técnica operatoria utilizada.

En lo que respecta a la incidencia, datos de Ferris-135 y Odel, Lapides220, Doroshaw-111, Creevy-96, Jacobs-
189 y Stirling, Wilkinson-423, Kusonoki-216 y 217 y cols., y Wehener-413 y Brosig, demostraron que las alteraciones electrolíticas ocurren en $60.4 \%$ de las pacientes, de las cuales, en $68.7 \%$ se desarrolló hipercloremia y en $77 \%$, la acidosis. Acompañando casos de esta naturaleza por 3 a 4 años, Berglin-36 y Mathisen y también Pers-321, han verificado que estas alteraciones electrolíticas alcanzan $100 \%$ de las pacientes.

Estas alteraciones electrolíticas y metabólicas han sido relacionadas a varios factores: 1. A la absorción de los constituyentes urinarios (cloro, radicales ácidos, derivados fenólicos, amoníaco y urea) por la mucosa intestinal (Goldschmidt-152 y Dayton, Visscher-405 y cols., Ferris-135 y Odel, Boyce-47, Boyce-48 y Vest, Foster-137 y cols., Mitchel-286 y Valk, Doroshow-111, Annis9 y Alexander, Parson-315-316 y cols., Rosemberg-348, Bohne-42 y Rupe, y D'Agostino-102); 2. A la insuficiencia renal consecuente a la lesión tubular determinada por la infección ascendente (Lapides-220 y Pers-321) y aumento de presión en el tracto urinario (Kekwick-204 y cols., Berglin-36 y Mathisen); 3 . A la pérdida de bases por la mucosa intestinal irritada (Boyce-47, Wilkinson-423, Doroshow-111 y $D^{\prime}$ Agostino-102); 4. Al factor hipopotasemia (Foster-137 y cols., Koremberg213, Dieffenbach-108 y cols., Wilkinson -423, Matern-257, Pyrah-331 y 332 Skanse-375 y Loughlin-225 y Stamey337 y Scott), atribuído a su mayor excreción renal, mayor secreción intestinal, mayor utilización por el epitelio tubular y por la ingestión reducida, en virtud de las náuseas y vómitos y, 5. Al 
factor deshidratación, explicado principalmente por la diuresis osmótica, motivada por la constante absorción intestinal del cloro, sodio y urea (Kekwick204 y cols., Kobemberg-213, Mitchell286 y Valk, y Stamey-377) por la pérdida crónica de líquidos del intestino (Wilkinson-423) y por la menor reabsorción hídrica al nivel de los túbulos lesionados (Berglin-36 y Mathisen).

De los factores citados, la insuficiencia renal es, sin embargo, la de mayor importancia en la determinación de los disturbios electrolíticos, consecuentes a las uréterosigmoidostomías. En una primera fase, los riñones, aun íntegros, consiguen compensar las alteraciones originadas de la reabsorción de substancias ya excretadas. De allí la manutención, dentro de límites normales, del equilibrio metabólico y electrolítico. Posteriormente y perjudicada la función renal, este desequilibrio se establece y se agravará progresivamente, en función de la reabsorción urinaria al nivel de la mucosa intestinal $\mathrm{y}$, principalmente, a costa del establecimiento de la insuficiencia renal.

Se concluye de lo que acabamos de exponer que las urétero-sigmoidostomías son operaciones graves, de técnica delicada y de pronóstico reservado, en virtud de las complicaciones que acarrean (estenosis de la boca anastomótica entre el uréter y el sigmoide, aumento de presión en el tracto urinario, reflujo, infección, absorción de los constituyentes urinarios y extravasamiento de orina en el área de la anastomosis).

Tres factores han contribuído para mejorar sus resultados: 1. Mejoramiento de la técnica, con obtención de boca anastomótica amplia y de mecanismo vulvular que, reduciendo las posibilidades del reflujo y del aumento de la presión en el tracto urinario, hace menor el riesgo de gravedad de la insuficiencia renal; 2. Uso de quimioterápi$\cos$ y antibióticos que, contribuyendo a la antisepsia del medio intestinal, reducen la incidencia de pielonefritis y de infección a nivel de la boca anastomótica y, principalmente, 3. Al mejor conocimiento de los disturbios metabólicos consecuentes de la derivación urétero-intestinal.

Sin embargo, todavía quedan tres complicaciones que permanecen insolubles (aumento de la presión intra-canalicular, infección ascendente y absorción de los constituyentes urinarios) y, por esto, se justifican las críticas serias que aún se hacen a la indicación de estas intervenciones.

Para evitar 'estos inconvenientes, han surgido nuevas técnicas basadas en la implantación de los uréteres en el asa intestinal aislada, constituyéndose lo que llamamos "neo-vejigas artificiales". Trabajos experimentales (Irvine-186 y cols., Murphy-300 y cols., Kusonoki-216 y 217 y cols., Mathisen-259 y cols.), y observaciones clínicas (Persky-322 y cols., Jude-199 y Smith), tienen demostrado, en lo que respecta a las perturbaciones metabólicas, la ventaja de las neovejigas sobre las urétero-sigmoidostomías.

De todos los tipos de vejigas artificiales, han sido preferidas la vejiga ileal, cuya técnica, sistematizada por Brickner-52 y 53, ha sido repetida con éxito por Eiseman-117 y Bricker, Cordonnier86, Stamey-377, y Scott y, entre nos- 
otros, por Cabral-63 y cols. Sin embargo, en relación a la urétero-sigmoidostomía, las neo-vejigas presentan gran desventaja. Incontinencia urinaria, exigiendo la presencia permanente, con sus inconvenientes, de un aparato colector de orina.

En este particular (incontinencia urinaria), la neovejiga constituída a costa del rectosigmoide, con colostomía terminal, sería preferible, pero en esta última técnica resulta una desventaja aún mayor: incontinencia fecal. En el momento actual, la simpatía de los autores se inclina para la neo-vejiga, pero la utilidad de la urétero-sigmoidostomía fue y lo es de tal orden, que ellas con seguridad no serán abandonadas.

\section{POSTOPERATORIO}

Las medidas postoperatorias constituyen, con las del preoperatorio y las de la técnica, el trípode en que se fundamenta el éxito quirúrgico del tratamiento de las fístulas urogenitales.

Es fundamental la continuidad de la terapéutica anti-infecciosa, que, iniciada antes de la intervención, debe proseguir por todo el período relacionado a los fenómenos de cicatrización y recuperación del organismo (hasta por 30 días).

En los casos de fístulas vaginales y uretrales, algunos autores (Burgos-59, Souza Rudge-352 y Azevedo-11), recomiendan el taponamiento vaginal (hasta por 48 horas) y prácticamente todos insisten en la imperiosa necesidad de perfecto drenaje vesical. Es realizada, por lo general, por la vía transuretral (con sonda de Foley) y raramente (en los casos de grandes fístulas vésicouretro-vaginales y uretro-vaginales), por la vía supra-púbica, manteniendo la sonda durante 10-15 días.

Para evitar los inconvenientes de una operación extra-numeraria, por la vía abdominal (Burgos-59), bajo la orientación de Peltier de Queiroz-333a se recomienda la ventaja del drenaje transvésico-vaginal (colpocistostomía) que practicó sin inconvenientes 13 veces en 20 casos de fístulas uretro-vésicovaginales.

El drenaje infra-sinfisario introducido por Stoeckel-352, aun cuando recordado por publicaciones más recientes (Azevedo-11), no ha resistido a la prueba del tiempo y no se justifica.

En los casos de urétero-sigmoidostomías se debe reducir los alimentos que presentan residuos, controlar las alteraciones electrolíticas y metabólicas (por la ingestión de líquidos azucarados y administración de suero fisiológico y potasio); pensar constantemente en la posible ocurrencia de obstrucción ureteral bilateral y no descuidar además de los antibióticos la quimioterapia (succinilsulfatiazol), que garantiza la esterilización del recto-sigmoide.

\section{PRONOSTICO.}

Dos cuestiones serán ventiladas: a) Curabilidad, y b) Relaciones con los fenómenos de la reproducción.

a) Curabilidad. Entre otros factores depende de la etiología y variedad de la fístula. Se sabe que las lesiones consecuentes a operaciones radicales (gran extensión), a la actinoterapia (is- 
quemia local) y a la necrosis isquémica (mortificación de los tejidos), son las de solución más difícil. Su corrección quirúrgica, dependiendo de la extensión de las lesiones, trae complicaciones que agravan definitivamente el pronóstico inmediato y tardío (derivaciones urinarias y neo-vejigas).

Desde el punto de vista de curabilidad, como ya lo decía Stoeckel-383, todos los autores admiten que las fístulas vésico-vaginales comprenden dos grupos: las que se acompañan de lesión uretral y del esfínter vesical (mal pronóstico) y las que no comprometen esas estructuras (buen pronóstico). En este último caso, aun cuando la lesión es extensa, Salgado-363, Moir-292, Lucas Machado-236 y Mahfouz-242, admiten su curabilidad siempre que la intervención sea orientada o ejecutada por técnico habituado y experimentado.

Para tener idea del grado de curabilidades de fístulas vésico-vaginales en general, presentamos el índice global de curas absolutas referido por autores cuya experiencia en este particular es notoria: Rudge (1941) 352-72, $1 \%$; Miller-277 (1942) 85,0\%; Phaneuf325 (1944) 98,2\%; Machado-236 (1945) 81,6\%; Hayes-163 (1946) $89,8 \%$; Harguindey-162 y Amenaza (1949) 91,0\%; Krishnan-215 (1949) 73,0\%; Carter-67 y col. (1952) 91,2\%; Burgos-59 (1953) 86,2\% ; Lana-219 (1954) 73,9\%; John-165 (1955) 68,0\%; Bowesman-50 (1955) 83,0\%; Bakowski (1956) 89,0\%; Counseller91 y Haigler (1956) 88,0\%; Mahfouz242 (1957) 100,0\%; Wenig - 415 (1958) $91,1 \%$; Salgado-363 (1960) $95.8 \%$ y Moir-292 (1961) 92,5\% .
El material presentado por cada uno de estos autores es de tal forma variable y diferente que no se justifica cualquier estudio comparativo de sus resultados. De un modo general el índice de cura, en el caso de fístulas vesicales y uretrales, está alrededor de 70-100\%. Considerando sin embargo los datos de los autores más familiarizados con su tratamiento, verificamos que el criterio de incurabilidad, exigiendo la derivación urinaria, no ultrapasó de 1,2\% (Salgado-363), 9,8\% (Rudge - 352), 2,1\% (Moir-292), 5,0\% (Azevedo11), 7,0\% (John-195), 11,5\% (Counseller-91 y Haigler), 2,0\% (Everett124 y Mattingly), 3,6\% (Lucas Machado-238), y 0,0\% (Mahfouz-242).

Por otro lado, la mortalidad quirúrgica inmediata alcanzó $1,5 \%$ (Salgado363 ), 4,8\% (Rudge-352), 1,3\% (Lana -219 ), 4,4\% (Wenig-415), 7,0\% (Barowski-23) y fue nulo para Azevedo11, Moir-292, Burgos-59, Carter-67 y cols. y Mahfouz-242.

En lo que respecta a las fístulas ureterales, el pronóstico es más delicado aún, en virtud de las complicaciones renales que pueden advenir del fracaso parcial o total de su tratamiento (insuficiencia renal y nefrectomía). Para fines de pronóstico, deben ser considerados entre otros, los siguientes factores: tipo de lesión (uni o bilateral, total o parcial), altura y extensión de la lesión, integridad vesical y uretral y condiciones funcionales de los riñones.

La cura espontánea de las fístulas uretrales, que según Carter-66 y Salaber-358 y Guixá, ocurriría, respectivamente en 50 y $66.6 \%$, traduce la fi- 
brosis y la obstrucción del uréter con consecuente hidronefrosis y sacrificio total de la función renal homolateral.

Las dilataciones ureterales y las ureterocistoneostomías son intervenciones relativamente benignas; sin embargo, no se puede decir lo mismo de la nefrectomía, de las anastomosis términoterminales, de la urétero-íleo-cistoplastia y de las urétero-sigmoidostomías.

Al revisar 740 urétero-sigmoidostomías (por la técnica de Coffey), Hinman Weyrauch-173, refieren una mortalidad total de $30 \%$. Everett-122 y Hill (1954), analizando 64 casos operados por la técnica de Coffey II, comprobaron hasta tres meses después de la intervención, la elevada mortalidad de 37.5\%; Preston-329 (1951), en 100 intervenciones y Roberts-346 (1944) solamente $14.4 \%$ entre 90 pacientes. Con el advenimiento de la quimioterapia, de los antibióticos, de las transfusiones de sangre y de los conocimientos relativos a las perturbaciones metabólicas e hidroelectrolíticas, consecuentes a las derivaciones urinarias, el pronóstico, aun serio, ha mejorado. Para mucho ha contribuído el advenimiento de nuevas técnicas y la revisión de Clarke-72 y Leadbetter, incluyendo 2,897 urétero-sigmoidostomías que demostró ser la técnica de Leadbetter la que mejores resultados propicia. Sin embargo, esta solución está lejos de ser la ideal. La indicamos solamente cuando en el tratamiento quirúrgico de las fístulas uro-genitales no podemos contar con la vejiga y la uretra. Preferimos, siempre que sea posible, practicar la neo-vejiga por la técnica de Bricker (con alza aislada del ídeo terminal) y en la vigencia de lesión irreparable de la vejiga o de la uretra, recomendamos con Johnson-196, Stomington-386 y Eiseman, Lowsley y Johnson-228, Michalovsky-274 y Modelski, Kiefer212 y Linke, Hinman Jr.-176, la práctica de la neo-vejiga rectal con colostomía perineal transesfinteriana. En esa operación se implantan los uréteres en el recto. Seccionando el colon sigmoide al nivel del promontorio, el recto pasa a funcionar como reservatorio de orina, y bajándose el segmento cólico seccionado, hasta hacerlo emerger por el esfínter anal, éste pasa a dar continencia fecal y urinaria.

Se evitan en esta forma los graves inconvenientes de las neo-vejigas (incontinencia urinaria) y de las uréterosigmoidostomías (infección urinaria y pérdida de la función renal).

b) Relaciones con los fenómenos de la reproducción. Consideramos la fecundidad y la evolución del ciclo puerperal, en la vigencia de la fístula y después de su curación.

\section{Fecundidad}

La presencia de la fístula uro-genital, aun cuando no lo impida, reduce sensiblemente la concepción. Explican este hecho la reducida actividad sexual (Stoeckel-383, Thompson-394 y Reichenmiller-341), las condiciones desfavorables del medio vaginal y la elevada incidencia de amenorrea (25-50\%), acompañada de ausencia de ovulación (Neme-302) y perturbaciones hormonales (Luisi-229).

En estas condiciones, la asociación con la gestación, que según Rudge-355 
y Ferreira alcanzaría la cifra de $24 \%$, no representa, por su frecuencia, problema clínico de grande importancia.

A título de curiosidad vale la pena referir, sin embargo, que la concepción, según observaciones raras de Lichtenstein, Hammerschlag, Menge y Montini, citados por Rudge-355, y Ferreira, puede ocurrir por la uretra por finísimos orificios de colpocleisis espontáneas y operatorias y hasta en la vejiga.

Corregido el trayecto fistuloso, el coito, salvadas las excepciones en que quedan estenosis vaginales y colpocleisis muy bajas, es perfectamente exequible $\mathrm{y}$, en consecuencia, se amplía el índice de fecundidad. Sin embargo, solamente debe ser permitido después de la consolidación cicatricial y con la recomendación de ser progresivo y cuidadoso.

\section{Evolución del ciclo puerperal.}

Según datos de Kroner (23 interrupciones prematuras entre 37 gestaciones), citado por Rudge-355 y Ferreira, y el material de estos últimos autores $(23 \%$ de abortos), la incidencia del aborto y partos prematuros sería mayor entre las portadoras de fístulas vesicales o uretrales.

Con ocasión del parto y en la dependencia de las condiciones del tracto genital (estenosis vaginal, extensión y fibrosis del trayecto fistuloso), la presencia de la fístula vesical y uretral justifica la ampliación de las indicaciones de la cesárea. Sin embargo, cuando el canal de parto presenta condiciones favorables, se puede permitir sin recelos el tránsito vaginal.
En las pacientes operadas y curadas del proceso fistular, la cesárea representa sin duda el mejor y más seguro método de parto. Esta recomendación válida en tiempo de Stoeckel-382 (1932) y Reichenmiller-341 (1938), tiene hoy más razón de ser, a la vista de los recursos anti-infecciosos, anestési$\cos$, técnicos y transfusionales de que disponemos. La histerotomía también se justificaría, a nuestro modo de ver, en los casos de fístulas uretrales o vésico-uretrales, que se siguieron de derivaciones urinarias y de anastomosis ureterales término-terminales. A pesar de los casos referidos por Fritsch-355, Hyman-182, Watkins - 411, Eberbach116 y Pierce, Cabot-62, Stevens-378, Mingazzini-285, Walters-409, Randall335 y Hardwick, en los cuales la solución por vía vaginal fue coronada de éxito, juzgamos con Mingazzini-285 y Green-160-Armytage, que la innocuidad relativa de la cesárea y el riesgo (aun cuando pequeño) de estiramientos y desinserciones de las anastomosis ureterales, justifican plenamente la vía abdominal.

\section{INCONTINENCIA URINARIA DE ESFUERZO}

\section{Introducción}

Una vez analizada la incontinencia urinaria debida a las fístulas uro-genitales, veamos ahora la incontinencia dicha de esfuerzo encontrada en los casos en que un trayecto fistuloso, anómalo, entre los tractos urinario y genital no existe, produciéndose la salida in- 
voluntaria de orina a través del canal uretral.

Aun cuando el concepto de incontinencia de esfuerzo no sea uniformemente aceptado por todos los autores, vamos a admitir y adoptar aquel propuesto por Ullery-401: pérdida involuntaria de orina a través de una uretra intacta, debido a un aumento de la presión intra-abdominal. La sinonimia es vasta. La denominación de incontinencia urinaria de esfuerzo, según Ullery401, fue dada por Holland, siendo ésta la más aceptada por la mayoría de los autores. Bonney-45 la denomina enfermedad de incontinencia diurna, y Bercow-35 de incontinencia ortostática. Insuficiencia del esfínter interno, incontinencia funcional e incontinencia uretral, son también denominaciones usadas. En rigor, ninguna de ellas satisface. Así como vamos a ver, las denominaciones -incontinencia del esfuerzo, ortostática y diurna-, se aplican solamente para fases de la enfermedad, no se adaptan a todos los casos. La designación de insuficiencia del esfínter interno debe ser abolida por no admitir más la existencia de un verdadero esfínter interno; incontinencia funcional propuesta por Martius-255, tampoco satisface, pues existen lesiones anatómicas músculofasciales determinando incontinencia. Finalmente, la denominación incontinencia uretral adoptada entre nosotros por Azevedo-10, 12, significando solamente que la pérdida de orina se hace por la uretra, diferenciándola de las fístulas, ha tenido últimamente mayor aceptación por parte de los autores. La denominación más acertada será, como veremos, incontinencia por alteración del meca- nismo de oclusión del orificio uretrovesical.

Nuestra finalidad en este relato es la de revisar, de modo sucinto, lo que últimamente se publicó sobre el problema de la incontinencia urinaria de esfuerzo y también exponer la conducta de los Servicios a que pertenecemos, frente a los casos de esta naturaleza, revelando los resultados obtenidos por nosotros.

Dedicaremos especial atención al problema de la etiopatogenia, de cuyo conocimiento depende el buen éxito de la terapéutica.

Etiopatogenia. Inicialmente algunas rápidas consideraciones sobre anatomía y fisiología de la micción antes de considerar propiamente la etiopatogenia.

Nociones de anatomía. Veamos algunas consideraciones de interés sobre la uretra; la vejiga, el cuello vesical y el aparato músculo-aponeurótico de sostenimiento de la pelvis.

Uretra. Con relación a la uretra, debemos señalar que los llamados esfínteres externo e interno no existen como estructuras individualizadas, como fueron descritos anteriormente por diversos autores (Heis, Ludinghausen, Zangemeister, Martius, Kalischer y Hartl).

El "esfínter interno" es dependencia de la propia musculatura de la vejiga (músculo detrusor), que al alcanzar el cuello vesical, envía fibras que abrazan el orificio uretro-vesical por delante y por detrás. Su existencia depende, por lo tanto, de la disposición de las fibras musculares vesicales a ese nivel y no de una estructura propia independiente. El "esfínter externo" decididamente no existe en la mujer. En el hombre 
es descrito como esfínter de uretra membranosa, teniendo importancia en el control de la micción. En la mujer, lo que se denomina el esfínter externo no pasa de fibras de los músculos superficiales del perineo: bulbo-cavernoso, transverso profundo y superficial y aun fibras medianas del pubo-coccígeo, que se insertan en la uretra. Por cierto, a través de la embriología se comprende bien esa diferencia, pues en la mujer no existe la uretra membranosa, siendo la uretra representada solamente por la uretra primitiva; el seno urogenital, que forma la uretra membranosa del hombre, en la mujer constituye el vestíbulo ampliamente abierto, con sus músculos disociados, constituyendo los músculos superficiales del periné que limitan el orificio vulvar. En la uretra femenina debemos considerar separadamente sus dos terceras partes, $2 / 3$ anteriores $y$ $1 / 3$ posterior. Los $2 / 3$ anteriores no tienen importancia alguna en la incontinencia de orina, ejerciendo la función solamente conductora y orientadora del chorro urinario; tanto así que podemos resecar las $2 / 3$ anteriores de la uretra, sin que haya incontinencia de orina. El $1 / 3$ posterior verdaderamente tiene importancia en el control urinario y vamos a considerarlo al estudiar el cuello vesical, o sea, aquella zona de transición entre la vejiga y la uretra.

Vejiga. La musculatura de la vejiga es representada principalmente por el músculo detrusor, con una disposición de fibras en espiral. Al alcanzar el cuello de la vejiga, forman asas que circundan la parte inicial de la uretra, de modo de constituír lo que se dijo 1lamar el esfínter interno o liso de la ure- tra. En esta forma, la distensión del detrusor tiende a cerrar ese orificio y su contracción a abrirlo. Se debe aún considerar que la distensión de la vejiga se hace por cuenta de sus paredes laterales y cúpula, permanéciendo su base fija.

Cuello vesical. La zona de transición entre la vejiga y la uretra, donde se encuentra el orificio uretro-vesical que se denomina el cuello vesical, tiene, en la mujer, importancia fundamental en el problema de la incontinencia urinaria. Allí se localizan lo que podemos denominar de mecanismo de cierre de la vejiga o del orificio uretro-vesical. Para el perfecto funcionamiento de ese mecanismo, son necesarias las siguientes condiciones anatómicas: a) Posición del cuello vesical. En condiciones normales el cuello vesical permanece por detrás de la sínfisis púbica, y a ese nivel, la pared posterior de la uretra forma con la base de la vejiga un ángulo recto de apertura posterior. Esta posición del cuello vesical depende del sistema músculo-aponeurótico del piso pélvico, principalmente del músculo pubo-coccígeo. b) Musculatura de la vejiga. Resaltando anteriormente que las fibras del detrusor al nivel del orificio interno de la uretra presentan una disposición en espiral, con tendencia a cerrarlo en la distensión y mantenerló abierto en la contracción. c) Plejo venoso al nivel de orificio uretro-vesical. Descrito por Stieve-380 y Bercow-35, colabora en su cierre, ejerciendo un papel de impermeabilización, como podremos llamarlo.

A parato de sostenimiento. Está constituído por: a) Diafragma pélvico. For- 
mado por el músculo elevador del ano, siendo su componente pubo-coccígeo de importancia fundamental en la manutención del cuello vesical en su posición normal. El músculo pubo-coccígeo, además envía fibras para la propia pared uretral. b) Diafragma uro-genital. Dispuesto por fuera del primero y en cuya constitución entra el músculo transverso profundo del periné y la aponeurosis perineal media, que es atravesada por la uretra, contribuyendo para su manutención. Aún en este plano, tenemos el ligamento pubo-uretral de Krantz. -253 fijando la uretra a la parte posterior de la sínfisis púbica que tiene importancia en la génesis de la incontinencia, como veremos. c) Músculos superficiales del periné. Como ya vimos, entran en la constitución de lo que se denomina "esfínter externo" de la uretra. Su acción en el problema de la continencia, en la mujer, es dudoso.

Nociones de fisiología. Vamos a considerar la fisiología de la micción normal y el mecanismo de la continencia urinaria. El estudio de la micción representa problema aún controvertido, con innumerables teorías, no siendo nuestro propósito el de citarlas todas, ni discutirlas. Existe, sin duda, diferencia en cuanto a la micción en el niño y en el adulto, difiriendo también en éste según se trata de hombre o mujer. En el niño, hasta más o menos 1 año de edad, la micción resulta de la contracción del detrusor, siendo un fenómeno reflejo de automatismo medular. El estímulo para la producción de este reflejo es representado por la distensión de la pared vesical, las vías aferentes y eferentes están constituídas por los ner- vios parasimpáticos (nervios pélvicos o erigentes), relacionados con segmentos medulares S2, S3 y S4, donde se encuentra situado el centro reflexógeno. Del primer año en adelante y gracias a la mielinización de los sistemas superiores, la acción del factor voluntad viene a complicar este mecanismo reflejo simple.

En la micción normal de la mujer adulta, existen dos fases: Fase voluntaria y fase refleja. En la primera fase o voluntaria que inicia la micción, consiste en la bajada del cuello vesical, dependiendo de la musculatura estriada del piso pélvico. La segunda fase o refleja consiste en la contracción del detrusor con el vaciamiento de la vejiga. Este reflejo de la contracción del detrusor tiene dos estímulos: la distensión de la pared vesical y la bajada del propio cuello vesical. En esta forma, con la presión intra-vesical de $12-26 \mathrm{~cm}$. de agua, que equivale a un contenido de más o menos 250 c.c. de orina, aparece el deseo a la micción; con presión de 25-40 cm. de agua, la micción es imperiosa. Sin embargo, y es en este punto donde interviene el factor voluntad, mientras no haya bajada del cuello vesical (fase involuntaria) por el relajamiento de la musculatura estriada del piso pélvico, en particular el músculo pubo-coccígeo, la micción no se inicia. La micción es iniciada entonces por el relajamiento de la porción pubo-coccígea del elevador del ano, siendo el cuello vesical dislocalo hacia abajo, constituyendo este hecho el estímulo fundamental para la contracción del detrusor. La bajada del cuello vesical coloca la porción inicial de la uretra en posi- 
ción ideal para facilitar el vaciamiento de orina. Este mecanismo así expuesto explica fácilmente: 1. Cómo provocar la contracción de la vejiga con pequeña cantidad de orina en su interior. 2. La capacidad de impedir, bajo acción de la voluntad, la contracción del detrusor, aun con la vejiga llena. 3. La capacidad de cortar (sostener) el chorro urinario durante la micción.

En lo que se refiere a la continencia urinaria, existen diferencias fundamentales entre el hombre y la mujer. En el hombre, tiene importancia el esfínter estriado de la uretra membranosa; el cuello vesical no sufre alteraciones en su posición normal, sostenido como es, por la próstata y por la musculatura del piso pélvico, que no está sujeta a relajamientos y roturas, como suele suceder en la mujer. La incontinencia urinaria en el hombre es por lo tanto excepcional. En la mujer, sin embargo, la continencia de orina no depende de mecanismos esfinterianos sino, fundamentalmente, del cuello vesical, cuya posición está en la dependencia de la musculatura del piso pélvico, en particular del haz pubo-coccígeo del elevador del ano. Por lo tanto, hecho interesante, la continencia urinaria en la mujer está en la dependencia directa de un músculo extraño al aparato urinario, el cual es el músculo pubo-coccígeo.

La continencia urinaria en la mujer está relacionada con: 1. Posición del cuello vesical; 2. Angulo posterior formado entre la uretra y la base de la vejiga; 3 . Plexo venoso al nivel del orificio interno de la uretra. En condiciones normales, en posición de reposo, el cuello vesical se sitúa por detrás del pubis, y a ese nivel la uretra forma con la vejiga un ángulo de apertura posterior. En estas condiciones, aun con la vejiga llena y presión intra-vesical elevada, la resultante de fuerzas actúa sobre la base de la vejiga, no permitiendo el vaciamiento de orina.

El relajamiento del músculo pubococcígeo, con el descenso del cuello vesical, deshace el ángulo posterior y viene a colocar el orificio interno de la uretra en la posición favorable para el vaciamiento de la orina. Como la bajada del cuello vesical representa estímulo para la contracción del detrusor, la micción se inicia. Del mismo modo, con los aumentos de presión intra-abdominal, que se reflejan sobre la presión intra-vesical, es el músculo pubo-coccígeo el que, manteniendo el cuello vesical elevado, garantiza la continencia.

Finalmente, el plejo venoso que circunda el orificio interno de la uretra tiene también su papel en el cierre de ese orificio, como que, impermeabilizándolo, impide en esta forma el extravasamiento.

De lo expuesto se concluye que dos son los factores responsables por la incontinencia urinaria de esfuerzo en la mujer: 1. Deficiente cierre del orificio interno, bajo condiciones que determinan aumento de la presión intra-abdominal. 2. Incapacidad de las formaciones músculo-aponeuróticas de la pelvis, en particular del músculo pubo-coccígeo, en evitar la bajada del cuello vesical bajo la acción del esfuerzo, cuando hay un aumento de la presión intra-abdominal. 
De estos factores, el segundo es el nás importante y el más frecuente, siendo responsable por la gran mayoría de los casos de incontinencia que nos llegan a nuestras manos. Con el relajamiento del piso pélvico, principalmente del músculo pubo-coccígeo, del cuello vesical, cuya posición normal está en la dependencia directa de la acción de este músculo, se va a presentar en posición más baja, habiendo también concomitantemente, apagamiento o desaparición del ángulo posterior entre la uretra y la vejiga. Podríamos, entonces, decir que la mujer con incontinencia urinaria de esfuerzo ya está en la primera fase de la micción, como explicamos antes. Así, siendo un aumento de la presión intravesical consecuente a cualquier aumento en la presión abdominal, determinará el vaciamiento, más o menos intenso, de orina por la uretra, caracterizando el cuadro de la incontinencia urinaria de esfuerzo.

Este concepto, así esquematizado, se comprobó con la documentación suministrada por estudios radiológicos (uretrocistografías en posición de reposo, de esfuerzo y miccionales).

Entre los trabajos iniciales sobre el estudio radiológico en la incontinencia urinaria de esfuerzo, debemos destacar Mikulicz-Radecki-276 en Alemania, en 1931, y de Vicente de Azevedo-13 y Cabelo Campos entre nosotros, en 1932. Cupo a estos últimos autores la primacía de haber descrito la modificación de forma y posición del cuello vesical en la incontinencia, caracterizada por lo que ellos denominaron de "señal del cuello" (10 y 12). Millin-284 y Read en 1948, dieron un grande em- puje al estudio radiológico dinámico en la incontinencia urinaria de esfuerzo. Dignos de mención son aún los trabajos posteriores de Muelner-298 y 298-a, Hodgkinson-17, 97-177, Ball, Douglas y Fulkerson-24, 27, 28 en los EE. UU.; Jeffcoate-190-191 y Roberts-347 en Inglaterra y Tavolaro-388, entre nosotros.

Muelner y Hodgkinson-298-298 a177 , practicando cistografías en posición antero-posterior, en primíparas y multíparas en decúbito dorsal horizontal, en posición ortostática y durante el esfuerzo, pudieron verificar las modificaciones sufridas por el cuello vesical con relación a la forma y posición. Así notaron que en mujeres incontinentes, aun cuando en reposo, el cuello vesical se presenta en forma de embudo, situándose el orificio interno de la uretra en el esfuerzo, abajo del límite inferior de la sínfisis púbica, en la posición ortostática.

Ball, Douglas y Fulkerson-24-27-28, practicando cistografías en posición lateral en reposo y en el esfuerzo en mujeres continentes e incontinentes, pudieron observar que en estas últimas, al esfuerzo el cuello vesical viene a situarse por delante de una línea que representa la prolongación de la sínfisis púbica. En mujeres continentes, el cuello vesical, aun cuando en reposo, ya se encuentra en posición más cercana de la citada línea, ultrapasándola con ocasión del esfuerzo.

Finalmente, Jeffcoate-190-191 y Roberts-347, en el estudio radiológico, se preocuparon del ángulo posterior entre la uretra y la base de la vejiga. Observaron que en los casos de incontinencia, 
ese ángulo desaparece, presentándose la uretra en continuación directa con la base de la vejiga.

En síntesis, podemos decir que estos estudios radiológicos vinieron a demostrar que en las mujeres incontinentes vamos a encontrar una acentuación de lo que se encuentra en mujeres normales al iniciar la micción.

\section{Clasificación}

Puede ser congénita y adquirida. En esta última se distinguen 3 tipos: Postparto, post-operatoria y de la menopausia (climaterio).

El tipo congénito es raro, pocas veces visto por el ginecólogo, siendo condicionado a una deficiencia de la inervación de la musculatura de la vejiga, de la musculatura del piso pélvico o de la propia pelvis ósea. La adquirida en el post-parto es la más común, debido a una lesión traumática del aparato músculo-aponeurótico de sustentación de la pelvis, condicionada al parto. La postoperatoria se sigue a una intervención ginecológica ya sea por la vía alta o ya sea por la vía vaginal. La paciente que no presentaba incontinencia urinaria de esfuerzo, pasa a presentarla después de la operación. Por la vía abdominal puede ocurrir en operaciones radicales para el tratamiento del carcinoma del cuello del útero, en que una exéresis excesiva del piso pélvico perjudicó la sustentación de la vejiga y uretra, alterando la posición del cuello vesical. Por vía vaginal suele suceder en operaciones para la cura del prolapso genital con cistocele, sin queja de incontinencia urinaria de esfuerzo.
Por cierto este problema de cistocele e incontinencia urinaria de esfuerzo es interesante. Las dos entidades pueden existir separadamente, aun cuando en la mayoría de las veces estén asociadas. La incontinencia que se presenta después de una operación para la cura del cistocele no es de difícil explicación. En estos casos, aun cuando exista en la mayoría de las veces una acentuada caída del cuello vesical, la incontinencia urinaria de esfuerzo no se presenta, porque la presencia del cistocele, que es retrotrigonal, hace que el ángulo posterior no solamente esté conservado, sino hasta exagerado. Cuando se hace una operación plástica para corregir el cistocele, como consecuencia ahora de intervención, desaparece el ángulo posterior, permaneciendo el cuello vesical en posición baja, criando por lo tanto las condiciones para que la incontinencia se instale. En estos casos, por lo tanto, en que hay cistocele sin incontinencia, debemos considerar las pacientes como portadoras de una incontinencia potencial y operarlas como si hubiese incontinencia de esfuerzo, recolocando durante la intervención el cuello vesical en su posición ideal. Ball-26 denomina a este tipo de incontinencia, potencial.

Otro tipo de incontinencia post-operatoria sería el consecuente a la oclusión de las fístulas vésico-vaginales que interesan a la región del cuello vesical $\mathrm{y}$, por lo tanto, de las fístulas, —mejor dichas, uretro-vésico-vaginales. Muchas veces en estos casos se consigue una perfecta oclusión de la fístula, pero la paciente pasa a presentar incontinencia de esfuerzo, por lo general en grado acentuado. Volveremos a este tipo de 
incontinencia al tratar de la terapéutica quirúrgica.

Finalmente la incontinencia de esfuerzo de la menopausia o del climaterio es la que se manifiesta en esta fase de la vida de la mujer, en que la atrofia y el relajamiento de los músculos y fascias del piso pélvico y periné - condicionados por la falta de estrógeno-- se asocia a una incompetencia del plejo venoso que existe a nivel del orificio interno de la uretra. En la mayoría de las veces existía ya una incontinencia de pequeño grado, que se intensifica ahora por la acción de los factores supracitados.

\section{Sintomatología}

El síntoma fundamental está representado por la pérdida de orina a través de la uretra, condicionada por cualquier aumento de la presión intra-abdominal. Naturalmente existen grados de incontinencia, desde la incontinencia liviana, que tiene lugar en la vigencia de un esfuerzo intenso, hasta la incontinencia total de orina, en que la lesión del mecanismo de oclusión del orificio uretrovesical es tan acentuada que la paciente no consigue retener ninguna cantidad de orina en el interior de la vejiga. Consideraremos 4 grados de incontinencia, de acuerdo con Henriksen-164. Así tenemos: Grado I. Incontinencia condicionada por aumento súbito de presión intra-abdominal, como la risa, la tos, el estornudo, etc. Grado II. Incontinencia que se presenta en la posición ortostática, principalmente en la deambulación. Grado III. Incontinencia de carácter casi continuo, en que la pa- ciente, aun acostada, pierde pequeñas cantidades de orina por la uretra. Grado IV. Incontinencia total o completa, en la cual la paciente no consigue presentar micciones, una vez que prácticamente la orina drenada por los uréteres, fluye a través de la uretra.

Muchas veces, además del síntoma incontinencia, vamos a encontrar lesiones irritativas de la mucosa y de la piel de la región vulvo-perineal, por la maceración provocada por el flujo de orina. Finalmente, síntomas nerviosos y psíquicos pueden presentarse, dependiendo naturalmente de la constitución neuro-psíquica de la paciente, habiendo casos en que una verdadera neurosis puede instalarse. Es menester decir que muchas veces la incontinencia está asociada con otras enfermedades, como prolapso genital, lesiones de la columna, lesiones del sistema nervioso, etc., habiendo casos en los cuales en la sintomatología tenemos que considerar los síntomas dependientes de la patología asociada.

\section{Diagnóstico}

Aquí debemos considerar: Anamnesis, examen físico (examen físico general, examen ginecológico y prueba de elevación del cuello vesical), uretrocistoscopia, uretrocistografía y cistometría.

En la anamnesis procuramos no solamente verificar la existencia de una incontinencia urinaria de esfuerzo, pero también su grado. Los antecedentes obstétricos y quirúrgicos tienen su interés. De la misma forma debemos investigar datos que puedan sugerir la existencia 
de lesión del sistema nervioso o de la columna vertebral.

El examen de la paciente debe ser iniciado con un examen clínico general. $\mathrm{Si}$ en la anamnesis se sospecha de la existencia de un factor neurógeno, un examen neurológico hecho por un especialista, así como radiografías de la columna lumbo-sacra, son indispensables.

Por el examen ginecológico podemos comprobar verdaderamente el vaciamiento de orina o de líquido introducido en la vejiga (200-300 c.c.), a través de la uretra, cuando la paciente es solicitada a hacer esfuerzos. Se verifica también la existencia y el grado, sea de cistocele o de prolapso uterino, así como de rotura del periné y el relajamiento del piso pélvico. Finalmente, se comprueba la existencia de otras ginecopatías asociadas, como tumores del útero y anexiales. La existencia de ginecopatías asociadas a la incontinencia urinaria de esfuerzo tiene importancia en la conducta quirúrgica futura.

Una vez comprobada la existencia de incontinencia de esfuerzo, se practica la prueba de la elevación del cuello vesical, que tiene importancia principalmente en el pronóstico de la intervención quirúrgica que se practicará. Esta prueba, original de Bonney-45, consiste en llenar la vejiga con $250-300$ c.c. de suero, verificándose cuando la paciente ejecuta un esfuerzo, el flujo del líquido por la uretra; entonces con 2 dedos colocados en la vagina, empujamos el cuello vesical hacia arriba, en dirección al pubis y con esta maniobra, siendo la prueba positiva, el flujo a través de la uretra, por el esfuerzo, no se producirá. Existe una variante de esta prueba descrita por Marshall, Marchetti y Krantz253, que consiste, en las mismas condiciones de la prueba, practicar en la pared vaginal anterior, en la altura del cuello vesical un botón con anestésico local, al cual se fija una pinza de Allis. Elevándose esta pinza hacia arriba, en dirección al ombligo, la prueba será satisfactoria si hubiere continencia de orina. Siempre nos hemos utilizado de la maniobra de Bonney, indiscutiblemente la más sencilla.

La uretrocistoscopia debe ser un examen de rutina en los casos de incontinencia de orina, por las informaciones útiles que suministra. Con ella excluímos la presencia de fístulas, procesos inflamatorios, como uretrotrigonitis, tan frecuentes en la mujer, obteniendo aún informaciones que nos orienten en el diagnóstico de vejiga neurogénica. En los casos más acentuados de lesión del mecanismo de oclusión uretro-vesical se puede notar la desaparición o apagamiento del nivel del cuello vesical, así como de su anatomía. Ball-26 resalta la importancia de la uretroscopia como método de observación directa de la función del cuello vesical.

Las uretrocistografías y cistografías cuando son bien hechas, con placas en posición de decúbito y de pies y aun en reposo y bajo esfuerzo, nos pueden dar, por las características presentadas por el cuello vesical (variaciones de forma y dirección), el diagnóstico de este tipo de incontinencia, siendo fundamentales las placas laterales. Finalmente la cistometría, que a rigor hace parte del examen neurológico bien con- 
ducido, es fundamental en los casos en que se sospeche la presencia de una vejiga neurogénica.

\section{Profilaxis}

1. En la incontinencia post-parto, la profilaxis se resume en una buena asistencia al parto, evitándose al máximo los traumas maternos debidos principalmente a la acción de la cabeza fetal sobre la uretra, la vejiga y sus medios de sustentación. Determinadas intervenciones obstétricas, como la sinfisiotomía, deben ser evitadas por la lesión que determinan en los elementos del diafragma urogenital, con consecuente incontinencia de esfuerzo 31-427. Aún como profilaxis de este tipo de incontinencia, son aconsejados, sea en la gestación o en el puerperio, ejercicios musculares que restauren el tonus de la musculatura del piso pélvico, como más adelante veremos.

2. En la incontinencia post-operatoria en pacientes con prolapso genital, la operación plástica reparadora debe siempre dar al cuello vesical una posición ideal, aún en los casos en que la paciente no se queje de incontinencia de esfuerzo.

3. Ejercicios musculares. Anteriormente resaltamos el papel del músculo pubo-coccígeo en la incontinencia de esfuerzo. Todos los ejercicios con la finalidad de restaurar o de mejorar el tonus y la capacidad contráctil de ese músculo, de la musculatura del piso pélvico en una forma general, tienen interés y utilidad. Kegel y Jones-197202-203, han insistido en este particular, creando él mismo un aparato -el perineómetro- destinado a sistematizar los ejercicios que tienen la finalidad de contracción del músculo pubo-coccígeo.

Aun cuando no sea la única intención con los ejercicios musculares tratar y curar una incontinencia de esfuerzo, no se puede negar que ellos representan un complemento útil en el tratamiento, teniendo su valor en la profilaxis. Un ejercicio con esta finalidad, que se puede enseñar a las pacientes, consiste en la súbita parada del chorro urinario durante la micción, que en esta forma se procesará de modo intermitente. Esa interrupción brusca de la micción, como sabemos, solamente es posible por la elevación del cuello vesical, por contracción del músculo pubococcígeo.

\section{Tratamiento}

Puede ser clasificado en: Médico (medicamentoso y fisioterápico), endoscópico y quirúrgico.

Tratamiento médico. a) Medicamentoso: Está indicado principalmente en las mujeres próximas a la menopausia, en que la incontinencia se instala por falta de hormonas que actúan sobre el trofismo de la musculatura pélvica, como los estrógenos (95, 178 y 365). Los andrógenos tendrían una acción semejante, pudiendo también ser utilizados (287 y 406). El tratamiento hormonal puede ser usado aisladamente, en los casos leves (livianos), pero en general es utilizado como complemento del tratamiento quirúrgico en mujeres en el climaterio. Otros medicamentos, como la estricnina, vitaminas B1 y E, los anticolinérgicos, etc., fueron utilizados por 
diversos autores sin resultados satisfactorios en la verdadera incontinencia de esfuerzo.

b) Fisioterápico o funcional. Consiste en la reeducación de los músculos del piso pélvico y del periné, principalmente del pubo-coccígeo. Kegel y Jones (197, 202 y 203) fueron los grandes entusiastas de este método. Kegel idealizó un instrumento denominado perineómetro, compuesto de una cámara neumática, para colocar en la vagina en comunicación con un manómetro graduado en mm. de $\mathrm{Hg}$. (de 0-100), para la intensidad de las contracciones ejecutadas voluntariamente por la paciente, la cual puede en esta forma controlar sus ejercicios, verificando la mejoría obtenida. Kegel y Cols. (197-202 y 203) refieren hasta $90 \%$ de buenos resultados. Wharton y Henriksen-421, relatan también resultados satisfactorios.

La mayoría de los autores, sin embargo, echa mano de este tratamiento funcional como medida profiláctica o complementaria del tratamiento quirúrgico.

Tratamiento endoscópico. Consiste en la electro-coagulación del cuello vesical con la finalidad de provocar una retracción cicatricial del mismo. Es un tratamiento muy poco utilizado por los autores, siendo dudosos sus resultados. Daría resultado satisfactorio, según algunos, en casos leves de incontinencia. Nosotros no tenemos, con este método, ninguna experiencia.

Tratamiento quirúrgico. Representa el tratamiento de elección, aun cuando no siempre el resultado obtenido sea satisfactorio. El número de operaciones descrito para la cura de la incontinencia de esfuerzo, según Ercole-120, alcanza a 85 casos, no siendo nuestro propósito considerarlas todas en este trabajo.

La recidiva de la incontinencia es grande, dependiendo evidentemente de la edad de la paciente, del grado de incontinencia, de la operación practicada y de la habilidad del cirujano en hacerla. Aumenta (la recidiva) también con el pasar del tiempo. Diversos autores, como Millin-283, Read-337-38, Kennedy-210, Te Linde-389, Aldridge-5, Fulkerson-147, y Counseller-90, refieren recidivas hasta de $30 \%$ con el uso de la vía vaginal. En anterior trabajo en que analizamos el material de la Clínica Ginecológica de F. M. U. S. P., hemos podido comprobar una recidiva de $21.3 \%$ (150). Recientemente Wood425 revela $38 \%$ y Machado-238, un porcentaje de $38-40 \%$ de recidivas.

Evidentemente las intervenciones que ofrecen mejores resultados con aquellas que procuran restaurar la posición del cuello vesical y el ángulo posterior entre la uretra y la vejiga.

Las intervenciones más comúnmente aceptadas para el tratamiento de la incontinencia pueden ser clasificadas en 3 grupos, según la vía de acceso: Vía vaginal, Vía combinada (vaginal con supra-púbica) y la vía supra-púbica exclusivamente. En cada una de las vías citaremos solamente las operaciones más aceptadas por la mayoría de los autores Ercole-120, Ullery-401 y Vernet-404, clasificaron de modo completo y racional todas las operaciones descritas para la cura de la incontinencia. 
1. Vía Vaginal. Fue la primera vía utilizada, debiéndose notar la tendencia de la mayoría de los ginecólogos a intervenir exclusivamente por la vía vaginal, utilizándose las otras vías en los casos de fracaso por la primera (la vaginal).

Considerando que la mayoría de los casos de incontinencia se asocia con el prolapso genital de algún grado, se comprende el porqué de ese procedimiento. Esta vía la vamos a considerar:

a) Operaciones que consisten en pliegues y refuerzo del cuello vesical y uretra. Son las operaciones más utilizadas, presentando sin embargo gran número de variantes o de modificaciones. La operación original es la de Kelly (205, 206) descrita en 1912; sin embargo, procedimientos semejantes fueron descritos por Marion-248-249, en 1937, y por Te Linde-389 en 1947, Kennedy, además de introducir algunas modificaciones en la operación de Kelly, difundió su uso, razón por la cual muchos la denominan de operación de KellyKennedy. La técnica más utilizada actualmente es la propuesta por Te Linde, que ejecuta el pliegue en toda la extensión de la pared vaginal anterior.

En estas intervenciones es fundamental el reconocimiento del nivel en que se encuentra el cuello vesical, lo que puede fácilmente ser hecho con una sonda de cabeza (Malecot, Pezzer o Foley), previamente colocada y ligeramente traccionada, reconociéndose a la palpación la cabeza de la sonda exactamente al nivel del cuello. En la técnica de Watson-412, este hecho es fundamental para que el cuello se sitúe por detrás de la sínfisis. Pacey-312 introdujo en estas operaciones una modificación bastante útil que consiste en la unión en la línea mediana, de los haces más medianos de los músculos pubo-coccígeo, inmediatamente abajo de la uretra y del cuello vesical.

b) Operaciones que consisten en la interposición muscular o aponeurótica entre el cuello vesical y la vagina. Estas operaciones tienen por finalidad, en último análisis, obtener una fibrosis para la sustentación del cuello vesical. Entre otras, podemos citar la de Martius-255 (músculo bulbo-cavernoso), Goodwin-153 (isquio-cavernoso), Ingelman-Sundberg-184 - 185 (pubo-coccígeo), Schauta-Wertheim (interposición vésico-vaginal del útero), Shaw-373 (fascia lata) y Kasdon-200 (ligamentos redondos ).

2. Vía combinada. Fue muy utilizada en los casos de fracaso de la vía vaginal o en los casos de incontinencia de grado más acentuado. Consiste en la confección de un alza músculo-aponeurótica (tiempo abdominal o suprapúbico), que era después halada hacia la vagina, siendo suturada bajo el cuello vesical (tiempo vaginal). También son llamadas operaciones de anillo músculofascial con la finalidad de elevar el cuello vesical en los momentos de contracción de la pared abdominal. Verdaderamente, lo que se conseguía con estas operaciones era una fibrosis cicatricial que sostenía el cuello vesical. Su aplicación hoy en día es muy limitada, siendo pocos los autores que de ella se utilizan.

Tenemos aquí también las operaciones de Goebell-Stoeckel (anillo constituído por el músculo piramidal y la 
aponeurosis del recto anterior del abdomen) y Aldridge-4 (semejante a la anterior, siendo, sin embargo, los retazos aponeuróticos transversales), ésta última la más usada actualmente. Ball25-26 recientemente pasó a recomendar la vía combinada para la cura de la incontinencia urinaria de esfuerzo, como veremos.

3. Vía supra-púbica. La vía suprapúbica exclusiva representa una adquisición reciente para la ginecología en el tratamiento de la incontinencia urinaria de esfuerzo. Entre las operaciones que se utilizan de esta vía, debemos citar la uretro-cérvico-cistopexia pubiana de Marshall, Marchetti y Krantz-247 y 253 , que por los excelentes resultados proporcionados, representa quizás la mejor arma de que disponemos hoy en día en la lucha contra la incontinencia urinaria de esfuerzo. Verdaderamente esta operación es la que mejor consulta a la etiopatogenia actualmente admitida para la incontinencia, dando al cuello vesical una posición ideal, difícilmente conseguida por otra intervención.

Todavía en la vía supra-púbica exclusiva, podemos acrecentar la operación de Millin-Read-284, que hace parte de las operaciones llamadas de anillo, en que el asa aponeurótica es pasada bajo la uretra, sin el tiempo vaginal. Finalmente, tenemos la operación descrita por Ball-25-26, que es también una uretro-cérvico-cistopexia, en que los puntos son fijados todos a la aponeurosis del recto anterior del abdomen, siguiéndose un tiempo vaginal y siendo por lo tanto, una técnica combinada.

En los casos de fístulas uretro-vésicovaginales, en que la incontinencia uri- naria de esfuerzo puede ocurrir, aun con la oclusión perfecta del orificio fistuloso, debemos acrecentar en el acto operatorio, según el caso, los pliegues tipo Kelly-Kennedy, la operación de Martius, de Shaw o de Schauta-Wertheim (estas por vía vaginal), la de Aldridge por vía combinada o la de Marshall-Marchetti-Krantz por vía supra-púbica, procurando de este modo impedir el fracaso de la operación para la cura de la fístula.

Nuestra conducta en los casos de incontinencia urinaria de esfuerzo. Como ya lo hemos dicho en el principio, fue en gran parte debido a la alta incidencia de recidivas con operaciones practicadas exclusivamente por la vía vaginal y de real agrado de los ginecólogos que el problema de la incontinencia urinaria de esfuerzo, inclusive también en las clínicas a las cuales pertenecemos, pasó a ser encarado con más cuidado, estudiándose mejor su etiopatogenia y su tratamiento, para que el resultado obtenido pudiera ser más compensador.

De ese estudio resultó nuestra conducta actual frente a los casos de incontinencia y que pasamos a exponer.

En trabajo anterior -150- analizamos el material de la Clínica Ginecológica de la F. M. U. S. P. (servicio del profesor José Medina), exponiendo nuestra experiencia con los diferentes tipos de operación, revelando una recidiva de $2.35 \%$ con la vía vaginal exclusiva, en casos de incontinencia. Deseamos también señalar en esta oportunidad la experiencia de uno de nosotros (J. R. A.), con la operación de Marshall-Marchetti-Krantz, en 85 casos. operados. 
Frente a un caso de incontinencia de esfuerzo comprobada, en el que el examen bien conducido, como ya lo dijimos antes, permite excluír otras causas de incontinencia, procuramos determinar dos factores de importancia en la conducta por seguir: grado de incontinencia y ginecopatía asociada, o sea, existencia o no de prolapso y su grado y aun existencia de tumor uterino o anexial, que requiera laparatomía. En la evaluación del grado de incontinencia practicamos la prueba de Bonney, actualmente y de modo sistemático.

Con base en los 2 factores considerados, nuestra conducta es la siguiente:

1. Pacientes portadoras de prolapso genital e incontinencia urinaria de grado liviano o medio: operación vaginal para la cura del prolapso con corrección de la incontinencia y, al mismo tiempo, con la operación tipo Kelly-Kennedy o de Te linde, practicada con el mayor cuidado, buscando la posición ideal para el cuello vesical. En este caso, la modificación introducida por Pacey y que consiste en la sutura de los haces más mediales o medianos del pubo-coccígeo, ofrece buenos resultados. La técnica de Watson es también interesante.

2. En los casos en que la operación por vía vaginal no consiguió curar la incontinencia, aun cuando la corrección del prolapso sea satisfactoria, la operación del Marshall-Marchetti se impone.

3. Pacientes con incontinencia urinaria de esfuerzo y sin cistoceles o solamente cistocele discreto: operación de Marshall-Marchetti. En estos casos, habiendo rotura del periné con o sin rec- tocele, la colpoperineorrafia completa la intervención.

4. Pacientes con incontinencia urinaria de esfuerzo y ginecopatía que exige para su tratamiento una laparotomía. Operación de Marshall-Marchetti, al mismo tiempo con la laparotomía.

5. Pacientes con prolapso genital e incontinencia urinaria de grado acentuado: operación de Marshall-Marchetti y operación vaginal para la cura del prolapso. En este grupo podemos decir, la conducta no es absoluta. Sin embargo, como la experiencia viene demostrando que en estas pacientes las recidivas son más frecuentes, nuestra tendencia es la de practicar la operación de Marshall-Marchetti desde un principio, juntamente con la operación vaginal y no practicarla posteriormente para la cura de recidiva que muchas veces tiene lugar. En líneas generales, esta ha sido nuestra conducta. En lo que se refiere al tratamiento por los ejercicios musculares con la finalidad de dar mayor tonicidad a los músculos pubococcígeos, hemos echado mano de ellos, principalmente de aquel que consiste en la interrupción del chorro urinario, no como medida exclusiva sino en el pre y en el post-operatorio.

Recientemente Wood-45, Machado238 y Fernández-133 han revelado conducta muy semejante.

La operación de Marshall-MarchettiKrantz representa por lo tanto la gran adquisición de nuestra conducta terapéutica actual, ofreciendo en los 85 casos operados, resultados altamente satisfactorios y así consagrando su caso. En 
trabajo que será publicado próximamente por uno de nosotros (J. R. A.), su indicación, su técnica y sus resultados son ampliamente analizados.

En nuestra serie de 85 casos, sin incluír ningún caso de historia inferior a 5 meses, hemos conseguido cura completa en 74 casos, o sea en un $87 \%$; en 5 casos obtuvimos lo que llamamos de cura relativa, es decir, se trataba de casos de incontinencia de grado acentuado que, después de la intervención permanecieron con discreta incontinencia a los mayores esfuerzos. Por lo tanto, resultados satisfactorios en 79 casos, o sea, en $93 \%$. Comparando los resultados obtenidos con el grado de incontinencia, vamos a observar que en los casos I, II y III, el porcentaje de cura fue de $95 \%$, mientras que en los casos de grado IV, fue apenas de $60 \%$. De los 6 fracasos, 3 eran de los grados I y II; uno era del grado III, y 2 eran del grado IV.

Considerando los casos en que la operación de Marshall - MarchettiKrantz, fue practicada después del fracaso o recidiva de la vía vaginal, el porcentaje de cura fue aquí de $90.7 \%$. El resultado es excelente, considerando, como bien lo señala Counseller-90, que si en estos casos insistimos en la vía vaginal, la segunda operación no dará porcentaje de cura superior a $50 \%$.

Los resultados obtenidos por nosotros con la operación de Marshall-MarchettiKrantz, son muy buenos, si los comparamos con los de otros autores (70, 110, 149, 192, 247, 253 у 401).

Por lo tanto, aun cuando no sea aplicable a todos sus casos, la operación de
Marshall-Marchetti-Krantz, por su ejecución sencilla, por el amplio campo operatorio que ofrece y por los buenos resultados que propicia, merece ocupar, entre las operaciones que procuran corregir la incontinencia urinaria de esfuerzo, una posición de relieve.

\section{CONCLUSIONES}

Las fístulas uro-genitales y la incontinencia urinaria de esfuerzo, teniendo en común la pérdida involuntaria de orina, son entidades distintas desde el punto de vista etiológico, pronóstico y terapéutico.

La discusión de estos temas, en congreso especializado, se justifica por varias razones: a) Por el incremento de la incidencia de fístulas de causas ginecológicas (quirúrgica y actinoterápica); b) Por las alteraciones metabólicas y electrolíticas consecuentes a las derivaciones urétero-intestinales, y c) Por la nueva orientación terapéutica en los casos de insuficiencia urinaria de esfuerzo.

\section{FISTULAS URO-GENITALES}

1. Las fístulas tocogenéticas por necrosis aún preponderan en los países subdesarrollados. La distocia ósea del estrecho medio es fundamental en su etiopatogenia.

2. En los países civilizados, la incidencia de fístulas uro-genitales se debe a la extensa indicación de la histerectomía (total), en la extirpación de las neoplasias benignas del útero y a la ampliación de las medidas terapéuticas, 
quirúrgicas y actinoterápicas en el tratamiento del cáncer del cérvix.

3. Las fístulas tocogenéticas se localizan de preferencia en la vejiga y la uretra. Aquellas de naturaleza ginecológica (quirúrgica y actinoterápica), por lo general son ureterales y vesicales.

4. Para fines de diagnóstico y pronóstico se recomienda en el examen de las portadoras de fístula uro-genital, el examen ginecológico (inclusive bajo narcosis), y el urológico (cistoscopia, urografía excretora y pruebas de función renal).

5. Entre las medidas profilácticas de las fístulas uro-genitales se recomienda: a) Reducir, en la asistencia al parto, la vía vaginal y ampliar la indicación de la cesárea en las anomalías pélvicas límites; b) Reducir al mínimo la disección de la vejiga en los casos de cesárea y de histerectomía total simples; c) En el tratamiento quirúrgico del prolapso genital, la disección del septo-vésico-vaginal debe ser hecha por cuenta del retazo vaginal principalmente, y d) En la cirugía radical del cáncer cervical el cirujano debe ser hábil y apto para evitar y corregir las posibles lesiones del tracto urinario.

6. La corrección quirúrgica de las fístulas vésico y uretro-vaginales debe ser intentada dos a tres meses después del accidente causal. En las fístulas ureterales ese plazo será de 30 días. Mientras se aguarda la oportunidad quirúrgica, se corrige el estado local y general, se combaten las afecciones asociadas, inclusive la infección, y en el caso de derivaciones urétero-intestinales, se pro- cede a la previa antisepsia del tracto intestinal.

7. En la cirugía de las fístulas vésico y uretro-vaginales se prefieren: para la vía vaginal, la posición de decúbito dorsal con sacro erguido y fuerte flexión y abdución de los miembros inferiores, la raquianestesia, los hilos absorbibles y la técnica del desdoblamiento.

8. Cuando la destrucción de la uretra es extensa y el aparato de cierre de la vejiga está comprometido, se recomiendan las técnicas de Kelly, Martius, Goebell - Stoeckel, las de IngelmanSundberg y las de Clovis Salgado.

9. La vía abdominal se restringe a los casos de fístulas de la cúpula vesical y de difícil acceso.

10. En la cirugía de las fístulas ureterales se utilizan las dilataciones y el cateterismo ureteral, las anastomosis término-terminales y las urétero-cistoneostomías.

11. En los casos considerados "incurables", se echa mano de la nefrectomía (cuando la función renal homolateral está comprometida y la contralateral íntegra), de las derivaciones urétero-intestinales (se prefiere la técnica de Leadbetter) y principalmente la técnica de las neo-vejigas (ileal y rectal).

12. Los grandes inconvenientes de las derivaciones urétero-intestinales (aumento de la presión canalicular, infección ascendente y absorción de los constituyentes urinarios), son reducidos o anulados con las neo-vejigas. 
13. El combate a la infección y el drenaje vesical permanente son medidas fundamentales en el post-operatorio de la cirugía de las fístulas uro-genitales.

14. Desde el punto de vista pronóstico son más serias las fístulas ureterales altas, con destrucción de segmento ureteral y las fístulas vésico-uretro-vaginales, con extenso comprometimiento de la uretra y del "esfínter" de cierre de la vejiga. En estos casos, el criterio de incurabilidad gira alrededor de 0 a $10 \%$.

15. La fecundidad y la fertilidad están reducidas en las fístulas urogenitales.

16. En las pacientes operadas y curadas de fístula la cesárea representa el mejor y más seguro método de parto.

\section{INCONTINENCIA \\ URINARIA DE ESFUERZO}

17. Con Ullery, admitimos ser la "incontinencia urinaria de esfuerzo" la mejor designación para la pérdida involuntaria de orina, a través de uretra intacta, debido al aumento de la presión intra-abdominal.

18. La revisión de los elementos anatómicos y funcionales, ligados a la micción, permite afirmar que son dos los factores responsables por la incontinencia urinaria de esfuerzo en la mujer: 1. El deficiente cierre del orificio interno de la uretra, y 2. La incapacidad de las formaciones músculo-aponeuróticas de la pelvis, en particular del músculo pubo-coccígeo, en evitar la ba- jada del cuello vesical bajo la acción del esfuerzo.

19. Para fines de diagnóstico y pronóstico, son útiles los datos de la anamnesis, examen ginecológico (inclusive la prueba de la elevación del cuello vesical), el examen urológico (uretro-cistoscopia y uretrocistografía) y el examen neuro-urológico (cistometría).

20. La profilaxis de la incontinencia urinaria de esfuerzo, post-parto (variedad más común), depende de las siguientes medidas de asistencia al parto: oportuno desbridamiento vulvoperineal, evitando las intervenciones como la sinfisiotomía; fórceps altos y medios y en la práctica de ejercicios de los músculos del piso perineal. La profilaxis de la variedad post-operatoria (en casos de prolapso genital), se hará por la elevación suficiente del cuello vesical.

21. En la terapéutica de la incontinencia urinaria de esfuerzo, las medidas de elección son: a) Fisioterapia (ejercicios para la re-educación de los músculos de piso pélvico y periné), y la cirugía.

22. En el tratamiento quirúrgico se utilizan 3 tipos de intervenciones: 1 . La vía vaginal (técnica de Kelly-Kennedy y de Te Linde); 2. La vía supra-púbica (técnica de Marshall-Marchetti-Krantz) y 3. La vía combinada (técnica de Aldridge y Ball).

23. Según la experiencia del Departamento de Obstetricia y Ginecología de la Facultad de Medicina de la Universidad de Sao Paulo (Servicio del profesor Medina), la operación de Marshall-Marchetti-Krantz representa la 
adquisición inigualable para la cura quirúrgica de la incontinencia urinaria de esfuerzo (95\% de curas completas en los casos grado I, II y III); $60 \%$ en los casos de grado IV y $90.7 \%$ en los casos en que la vía vaginal previa no fracasó.
24. La indicación de la operación de Marshall-Marchetti-Krantz no es universal. Las técnicas de Kelly-Kennedy y de Te Linde tienen lugar en la cirugía del prolapso genital con incontinencia urinaria de esfuerzo de grado leve y mediano.

1. ACOSTA-Sison, H.: Am. J. Obst. \& Gynec. 20: 239; 1930.

2. AHUmada, J. L.: Obst. y Ginec. Lat. Amer. 2: 264; 1944.

3. AHumada, J. C. y CALANDRA, D.: Obst. y Ginec. Lat. Amer. 10: 123; 1953.

4. ALDRIDGE, A. H.: Am. J. Obst. \& Gynec. 44: 398; 1942.

5. ALDRIDGE, A. H.: Am. J. Obst. \& Gynec. 51: 299; 1946.

6. ALdRIDGE, A. H.: J. Obst. \& Gynaec. Brit. Emp. 60: 1; 1953.

7. ALlen, E. P.: Brit. J. Radiology 20: 164; 1947.

8. ANNIS, D.: Brit. J. Urol. 25: 69; 1953.

9. ANNIS, D. and ALEXANDER, M. K. : Lancet 263: 603; 1952.

10. AZevedo, G. V.: Tese Fac. Med., Sao Paolo, 1938.

11. AZEVEDO, G. V.: An. Bras. Ginec. 17: 1, 1944.

12. AZevedo, G. V.: Rev. Gin. Obst. 98: 1; 1956.

13. Azevedo, G. V. e Cabelo Campos, J. M.: Rev. Ass. Paul. Med. 1: (6); 1932.

14. AZEVEDO, J. R.: Maternidade e Infância 15: 591; 1956.

15. AZevedo, J. R.: An. Cl. Ginec. Fac. Med. São Paulo 6: 255; 1958.

16. AZevedo, J. R.: Rev. Paul. Med. 54: 35; 1959.

17. AZEVEDO, J. R.: Maternidad e Infância 19: 221; 1960.

18. AZEVEDO, J. R.: Maternidade e Infância 20: 13; 1961.

19. AZEvedo, J. R. e cols.: Maternidade e Infância 17: 5; 1958.

20. AZevedo, J. R. e SÁ, C. P. F.: An. Paul. Med. Cir. 73: 327; 1957.

21. BAENA, A. F.: Rev. Bras. Cir. 8: 5; 1939.

22. BAKER, R. and MILLER, G. H. : J. Urol. 67: 638; 1952.

23. BAKOWSKI, L.: Zentr. f. Gynäk. 78: 401; 1956.

24. BALL, T. L.: Am. J. Obst. \& Gynec. 59: 1243; 1950.

25. BALL, T. L.: Am. J. Obst. \& Gynec., 63: 1245; 1952.

26. BALL, T. L.: Gynecologic Surgery and Urology. C. V. Mosby S. Louis, 1958.

27. BALL, T. L. e cols. : Am. J. Obst. Gynec. 59: 1252; 1950.

28. BALL, T. L. and FULKERSON, L.: Urol. Cut. Rev. 55: $591 ; 1951$.

29. BARElare, Jr., B. \& VEST, S. A.: Urol. and Cult. Rev. 46: 207; 1942.

30. BAUM, W. C. : J. Urol. 72: 16: 1954.

31. Bengolea, A. J.: Bol. Soc. Obst. Ginec. B. Aires 17: 234; 1938.

32. Bengolea, A. J. y BazterricA, E.: Rev. Med. Cir. Pat. Fem. 17: $141 ; 1941$.

33. BENSON, R. C. and HINMAN, F.: Am. J. Obst. Gynec. 70: 467; 1955.

34. BERCOW, S. G.: Am. J. Obst. \& Gyn. 41: 1051; 1941.

35. BERCOW, S. G.: Am. J. Obst. \& Gyn. 65: 346; 1953.

36. Berglin, T. and MAthisen. W.: Acta Chir. Scand. 104: 130; 1953.

37. BIANCO, A.: An. Bras. Ginec. 47: 135; 1959.

38. BITKER, M. P.: J. d'Urol. 60: 473; 1954. 
39. BLUM, E., et BADER, P.: Bull. Soc. D'Obst. et Gynéc. 8: 130; 1956.

40. BOEMINGHAUS, H.: Uretero-Sigmoidostomie und Darm-Ersatzblasenbildung. Georg Thieme, Stuttgart, 1956.

41. BOHNE, A. W.: J. Urol. 70: $581 ; 1953$.

42. BOHNE, A. W. and RUPE, C. E.: Surg. Gynec. Obst. 96: 541; 1953.

43. Bollman, J. L. and MANN, F. C.: Proc. Soc. Exp. Biol. Med. 24: 923; 1927.

44. BOND, W. and ROGERS, G.: Am. J. Obst. \& Gynec. 63: 215; 1952.

45. BONNEY, V.: J. Obst. Gynaec. Brit. Emp. 30: 358; 1923.

46. BOURQUE, J. R.: Brit. J. Urol. 29: $298 ; 1957$.

47. BOYCE, W. H. : J. Urol. 65: 241; 1951.

48. BOYCE, W. H. and VEST, S. A.: J.: Urol. 67: 169; 1952.

49. BOYD, J. D.: Am. J. Dis. Child. 42: 366; 1931.

50. BOWESMAN, C.: Irish J. Med. Sc. 352: 147; 1955.

51. BRamhall, T. C. and MARShall, D. F.: Am. J. Obst. \& Gynec. 60: 834; 1950.

52. BRICKER, E. M.: Surg. Clin. North America 30: 1511; 1950.

53. BRICKER, E. M.: Surgery 32: 372; 1952.

54. BRoWN, W. E. and SUtherland, C. G.: Am. J. Obst. Gynec. 77 : 862; 1959.

55. BRUNSCHWIG, A.: Total exenteration of the pelvic organs, In Meigs, J. V.: Surgical treatment of cancer of the cervix. N. York. Grune and Stratton, 1954.

56. BRUnschwig, A. and FRICK, H. C.: Am. J. Obst. \& Gynec. 72: 479; 1956.

57. BUCHERT, W. I. : J. Urol. 69: 665; 1953.

58. BUMM, E. : Trattado completo di ostetricia, Soc. Ed. Libraria, Milão 1923.

59. BURgos, J. F.: Tratamento das Fístulas Vésico-Genitais. Processo de Desdobramento. Tese Fac. Med. Univ. Bahia, 1953.

60. BURNS, R. A.: J. Urol. 74: 348; 1955.

61. CABOT, H.: New Engl. J. Med. 205: 706; 1931.

62. САВОT, H.: J. Urol. 35: 596; 1936.

63. CABRAL, A. D. e cols.: Rev. Paul. Med. 54: 460; 1959.

64. Calvo, R. B. e Fuentes, I. J.: Medicina 16: 283; 1948.

65. CAMARgos, A. L.: Rev. Ginec. D'Obst. 44: 458; 1950.

66. CARTER, R. G.: J. Urol. 71: 200; 1954.

67. CARTer, B. \& cols. : Am. J. Obst. \& Gynec. 63: 479; 1952.

68. CAUGHLAN, G. V.: J. Urol. 58: 428; 1947.

69. CAVALCANTI, R. C.: Informação pessoal, 1961.

70. CHAlmers, J. A.: J. Obst. Gyn. Brit. Emp. 59: 77; 1952.

71. CHARLEWOOD, G. P.: South African M. J. 27: 1129; 1953.

72. CLARKE, B. G. and LEADBETTER, W. F.: J. Urol. 73: 999; 1955.

73. COFFEY, R. C.: Ann. Surg. 50: 1238; 1909.

74. COFfey, R. C. : J. A. M. A. 56: 397; 1911.

75. COFFEY, R. C.: North Med. 24: 211; 1925.

76. COFFEY, R. C. : Surg. Gyn. Obst. 45: 816; 1927.

77. COFFEY, R. C.: Surg. Gyn. Obst. 47: 593; 1928.

78. COFfey, R. C.: North. Med. 29: 128; 1930.

79. COFFEY, R. C.: Brit. J. Urol. 3: 353; 1931.

80. COLby, F. H.: In Meigs, J. V.: Surgical Treatment of Cancer of the Cervix. Grune \& Stratton, New York, 1954.

81. COLlins, C. G. and JONES, F. B.: Obst. \& Gynec. 9: 533; 1957.

82. Collins, C. G. and cols.: Am. J. Obst. \& Gynec. 80: 1005; 1960.

83. CONGER, K. and ROUSE, P. V.: J. Urol. 74: 485; 1955.

84. CORDONNIER, J. J.: Surg. Gynec. Obst. 88: 441; 1949. 
85. CORDONNIER, J. J.: J. Urol. 63: 276; 1950.

86. CORDONNIER, J. J.: J. Urol. 74: 789; 1955.

87. CORDONNIER, J. J. and LAGE, W. L. : J. Urol. 66: 565; 1951.

88. CoRREA DA COSTA, C.: An. Bras. Ginec. 14: 334; 1942.

89. COUnSeller, V. S.: New York State J. Med. 45: 987; 1945.

90. Counseller, V. S.: J. A. M. A. 146: 27; 1951.

91. Counseller, V. S. and Haigler, F. H.: Am. J. Obst. \& Gynec. 72: 367; 1956.

92. COURI, A. A. : An. Bras. Ginec. 34: 25; 1952.

93. COURI, A. A.: Arq. Clin. Ginec. 5: 117; 1952.

94. COUVELAIRE, R.: Urol. Internat. 2: 1; 1956.

95. COUVElaire, R. et DREyfuS, P.: J. Urol. 58: 317; 1952.

96. CREEVY, C. D.: J. A. M. A. 151: 120; 1953.

97. CREEVy, C. D. and REISER, M. P.: Surg. Gynec. Obst. 95: 589; 1952.

98. CROSSEN, H. S. \& CROSSEN, R. J.: Operative Gynecology, Mosby Co., S. Louis, 1938.

99. CROWEll, J. A.: Am. J. Obst. \& Gynec. 24: 1266; 1957.

100. CUliner, A., Wets J.: Surg. Obst. \& Gynec. 64: 147; 1956.

101. CURTIS, A. H.: Obstetries and Gynecology, W. B. Saunders Co. Philadelphia, 1934.

102. D'Agostino, A. \& cols.: J. Clin. Invest. 32: 444; 1953.

103. DARGET, R. et BALLANGER, R. : J. d'Urol. 62: 3; 1956.

104. DAvidS, A. M. and LeSniCK, G. J.: Ann. Surg. 137: 389; 1953.

105. DAVIDS, A. M. and NEALON, R. F.: J. Urol. 78: 748; 1957.

106. DEMPSTER, W. J. and DANIEL, O.: Brit. J. Urol. 44: 225 ; 1956.

107. DEnNIS, E. J., \& cols.: Am. J. Obst. Gynec. 82: 727; 1961.

108. DiefenbaCH, W. C. \& cols.: New Engl. J. Med. 224: 326; 1951.

109. DODERLEIN, A. e KRONIG, B.: Ginecologia operatória, Salvat Edit. Barcelona, 1915.

110. Doolittle, L. H.: New Engl. J. Med. 246: 364; 1952.

111. DOROSHAW, H. S.: J. Urol. 65: 831; 1951.

112. DReicon, I.: Rev. Paul. Med. 52: 131; 1958.

113. DUNCAN, C.: Am. J. Obst. \& Gynec. 3: 513; 1938.

114. DUtra, L. H.: An. Bras. Ginec. 31: 199; 1951.

115. EAstman, N.: Williams Obstetrics, $1^{\text {a }}$ ed. Appleton-Century-Crofts. New York, 1950.

116. EBERBACH, C. W. \& PIERCE, J. M.: Surg. Gynec. \& Obst. 47: 540; 1928.

117. EISEMAN, B. and BRICKER, E. M.: Ann. Surg. 136: 761; 1952.

118. emmet, T. A.: The Principles and Practice of Gynecology, Lea Bros \& Co. Philadelphia, 1880.

119. Englund, S. \& cols.: Acta Obst. et Gynec. Scandinava 38: 68; 1959.

120. ERCole, R.: Anal. VI Cong. Am. y III Cong. Argent. de Urología, Mar del Plata 2: $23 ; 1957$.

121. EVERETT, H. S.: Urología Ginecológica e Obstétrica, Edit. Guanabara, Río, 1946.

122. EVeretT, H. S. and HILL, H.: Am. J. Obst. Gynec. 68: 1279; 1954.

123. EVEREtT, H. S. and MAtTingLy, R. F.: Am. J. Obst. Gynec. 71: 502; 1956.

124. EVERETT, H. S. and MATtingLy, R. F.: Am. J. Obst. \& Gynec. 72: 712: 1956.

125. EWERT, E. E.: Surg. Clin. North America 30: 927; 1950.

126. FABIAO, M. M.: Operações Ginecológicas, Edit. Briguiet, Rio, 1946.

127. FALK, H. C.: Clin. Obst. \& Gynec. 4: 229; 1961.

128. FALK, H. C. and BUNKIN, I. A.: Surg. Gynec. Obst. 93: ‘ 404; 1951.

129. FALK, H. C. and BUNKIN, I. A.: Obst. \& Gynec. 4: 4; 1954.

130. FALK, H. C. and ORKIN, L. A.: Obst. \& Gynec. 9: 538; 1957.

131. FALK, H. C. and TANCER, M. L.: Obst. \& Gynec. 3: 337 ; 1954. 
132. FALK, C. H. and TANCER, M. L.: Am, J. Obst. \& Gynec. 71: 97; 1956.

133. FERNANDES, M.: Informação pessoal, 1961.

134. Fernandes, M. e SÁ Leitao, A.: An. Bras. Gin. 30: 31; 1950.

135. FERRIS, D. O. and ODEL, H. M. : J. A. M. A. 142: 634; 1950.

136. FORET, J. and HANGSHEM, C.: Lancet, 24: 1181; 1953.

137. Foster, F. P. \& cols.: Lahey Clin. Bull. 6: 231; 1950.

138. FranCO, V. B.: Rev. Gin. D’Obst. 32: 63; 1938.

139. FRANK, R. T.: Surg. Gyn. Obst. 25: 538; 1917.

140. FRANZ, K.: Gynäkologische Operationen, Julius Springer, Berlim, 1925.

141. Freire, J. G. e AlmeidA, L.: Rev. Hosp. Clín. 8: 134; 1953.

142. Freitas, R. e cols.: Folia Clin. Biol. 17: 139; 1951.

143. Freitas, R. e SADI, A.: Rev. Ass. Méd. Bras. 2: 160; 1956.

144. Frinoviku, V. S. and SAVITSKAYA, L. K.: Akush. Ginec. 1: 46; 1956.

145. FRITSCH, H.: Dtsch. Med. Wschr. 1: 199; 1899.

146. FROMMOLT, G. und STAMATIADES, A.: Zentr. f. Gynäk. 38: 2242; 1934.

147. FUlKERSON, L.: Urol. Cut. Rev. 43: 569; 1952.

148. FỨTH, H. in Halban-Seitz: Biologie und Pathologie des Weibes, V vol., II tomo. Urban \& Schwarzenberg, Berlim, 1926.

149. Gallagher, W. T.: Am. J. Obst. Gynec. 63: $842 ; 1952$.

150. Gallucci, J. e Azevedo,, J. R. : An. Bras. Ginec. 51: 57; 1961.

151. GILlaM, J. S. e cols.: Lancet 72: 279; 1952.

152. GOLdschmidt, S. and DAYTON, A. B.: Am. J. Physiol. 48: 419; 1919.

153. GOODWIN, J. C.: Am. J. Obst. Gynec. 65: 65; 1953.

154. GOODWIN, W. E. \& cols.: Surg. Gynec. Obst. 97: 295; 1953.

155. GOODWIN, W. E. and THELEN, H. M.: Am. J. Obst. \& Gynec. 76: 641; 1958.

156. GOODWIN, W. E. and cols. : J. Urol. 80: 461; 1958.

157. GOODWIN, W. E. \& cols.: J. Urol. 81: 406; 1959.

158. GouveA, G. S.: Tese Fac. Fluminense Med. Rio de Janeiro, 1947.

159. GOUVERneur, R. et ABOUlker, P.: Rev. Chir. 68: 65; 1949.

160. GREEN-ARMYTAGE: Zbl. f. Gynäk. 52: 2326; 1928.

161. GUixá, H. L. y OtTuRi, J. E.: Sem. Méd. 104: 27; 1954.

162. HARguindey, J. S. and AmenazA, M. M. M.: Year Book obst. \& Gynec., pg. $422 ; 1949$.

163. HAYES, S. N.: Surg. Gynec. \& Obst. 81: $346 ; 1946$.

164. HenRIKSEN, E. : Am. J. Obst. Gynec. 66: 1121; 1953.

165. Hellstrom, J. and Romanus, R.: Acta Chir. Scand. 93: 439; 1946.

166. HESS, E. : J. Int. Col. Surg. 9: 517; 1946.

167. HIGGINS, C. C. : J. of Urol. 37 : 90; 1937.

168. HIGGINS, C. C. : J. Urol. 41: 464; 1939.

169. HIGGINS, C. C. : J. of Urol. 50: 657; 1943.

170. HIGGins, C. C. : J. Urol. 57: $693 ; 1947$.

171. HinMaN, F.: Proc. 7th Congress Int. Soc. Urology 1: 464; 1939.

172. HINMAN, F.: Calif. Med. 69: 433; 1948.

173. HiNMaN, F. and WeyraUCH, H. M.: Int. Abst. Surg. 64: 313; 1937.

174. HINMAN, F. and WEYRAUCH, H. M.: Surg. Gynec. Obst. 74: 129; 1942.

175. HINMAN Jr. F.: J. Urol. 64: 567; 1950.

176. HINMAN Jr. F.: J. Urol. 81: 126; 1959.

177. HODGKInSON, C. P.: Am. J. Obst. \&. Gynec. 65: 560; 1953.

178. HOFFMAN, F.: Zbl. F. Gynäk. 44: 2545; 1937.

179. Hoffman, H. A. e cols.: Rev. Paul Med. 54: 239; 1959.

180. HOLden, F. C.: Am. J. Obst. \& Gynec. 44: 880; 1942. 
181. HUdSON, P. B. and FOX, H.: Am. J. Obst. \& Gynec. 74: $368 ; 1957$.

182. HYMAN, A.: Am. J. Surg. 4: 435; 1928.

183. INGELMAN-SUNDBERG, A.: Gynaecologia 123: 380; 1947.

184. INGELmAN-SUNDBERG, A.: Acta Obst. Gyn. Scand. 30: 318; 1950.

185. Ingelman-Sundberg, A.: Acta Obst. Gyn. Seand. 31: 266; 1952.

186. IRVINE, W. T. \& cols.: Surg. For. 6: 593; 1955.

187. Itibere, D. V.: Rev. Med. Cir. São Paulo, 12: 451; 1952.

188. JACOBS, A.: J. Urol. 61: 517; 1949.

189. JACOBS, A. and STIRLING, W. B.: Brit. J. Urol. 24: 259; 1952.

190. Jeffeoate, T. N. A.: J. Obst. Gyn. Brit. Emp. 59: 685; 1952.

191. Jeffcoate, T. N. A. and RoberTS, H.: Am. J. Obst. Gyn. 64: 721; 1952.

192. JEFFCOATE, T. N. A. and ROBERTS, H.: Surg. Gyn. Obst. 98: 7434; 1954.

193. JEWETT, H. J.: J. Urol. 44: 223; 1940.

194. JEWETT, H. J.: J. Urol. 52: 536; 1944.

195. JOHN, M. P.: Obst. \& Gynec. Surv. 55: 761; 1955.

196. JOHNSON, T. H.: J. Urol. 73: 380; 1956.

197. JONES, E. C. and KEGEL, A. H.: Surg. Gynec. Obst. 94: 179: 1952.

198. JUDD, E. S.: Surg. Gyn. Obst. 30: 447; 1920.

199. JUDE, H. and SMITH: Surg. Gynec. Obst. 109: 173; 1959.

200. KASDON, S. C.: Urol. and Cut. Rev. 55: 597; 1951.

201. KASS: New England J. Med. 256: 556; 1957.

202. KEGEL, A. H.: J. A. M. A. 146: $915 ; 1951$.

203. KEGEL, A. H.: J. Int. Col. Surg. 25: 487; 1956.

204. KEKWICK, A. \& cols. : Brit. J. Urol. 23: 112; 1951.

205. Kelly, A. H.: Urol. and Cut. Rev. 17: 291; 1913.

206. KeLly, A. H. and DUMM, W. M.: Surg. Gyn. Obst. 18: 344; 1914.

207. Kelso, J. W. and FunNell, J. W.: Am. J. Obst. \& Gynec. 79: 856; 1960.

208. KENNEDY, W. T.: Am. J. Obst. Gyn. 41: 16; 1941.

209. KENNEDy, W. T.: Am. J. Obst. Gyn. 52: 206; 1946.

210. KENNEDY, W. T. : Am. J. Obst. \& Gynec. 69: 338; 1955.

211. KERR, W. S. and COLBY, F. H.: J. Urol. 63: 842; 1950.

212. KIEFER, J. H. and LINKE, C. : J. Urol. 79: 242; 1958.

213. KOREMBERG, M. : J. Urol. 66: 686; 1951.

214. KOTtMeIER, H. L.: Carcinoma of the Female Genitalia. Williams \& Wilkins, Baltimore, 1953.

215. KRIShNAN, R. G.: J. Obst. Gynaec. Brit. Emp. 56: $22 ; 1949$.

216. KUSONOKI, T. \& cols. : Urol. Internat. 2: 85; 1956.

217. KUSONOKI, T. \& cols. : Urol. Internat. 2: 26; 1956.

218. KUSS, R.: Chirurgie plastique et reparatrice de la voie excrétive du rein. Masson et Cie. París, 1954.

219. LANA, F. V.: Rev. Ginec. d'Obst. 48: 733; 1954.

220. LAPIDES, J.: Surg. Gynec. Obst. 93: 691; 1951.

221. LATZKO, W.: Am. J. Surg. 58: 211; 1942.

222. LEADBETTER, W. F.: J. Urol. 65: 818; 1951.

223. LEADBETteR, W. F. and CLARKE, B. G.: J. Urol. 73: 67; 1955.

224. Leitao, A. S.: Rev. Ginec. d'Obst. 103: 335; 1958.

225. Loughlin, J. F.: N. Engl. J. Med. 254: 329; 1956.

226. LOWER, W. E.: Ann. Surg. 112: 100; 1940.

227. LOWER, W. E.: J. Urol. 50: 581; 1943.

228. LOWSLEY, O. S. and JOHNSON, T. H.: J. Urol. 77: 173; 1957. 
229. LUISI, M. : Trans. Intern. Fourth Am. Cong. Obst. \& Gynec. C. V. Mosby Co. St. Louis, pg. $812 ; 1951$.

230. MACAGGI, G. B.: Arch. Ital. Urol. 22: 114; 1947.

231. MAC DONALD, S. A. and KATARIA, P. N.: J. Urol. 77: 437; 1957.

232. MACHADO, G.: Rev. Ginec. D’Obst. 35: 418; 1941.

233. MACHADO, L.: Rev. Ginec. D’Obst. 29: 471; 1935.

234. MACHADO, L.: Rev. Ginec. D’Obst. 30: 372; 1936.

235. MACHADO, L.: Rev. Gin. D’Obst. 2: 32 ; 1944.

236. MACHADO, L. M.: Obst. y Ginec. Lat. Amer. 3: 71; 1945.

237. MACHADO, L. M.: Rev. Gin. D'Obst. 102 : 555; 1958.

238. MACHADO, L. M.: Informação pessoal, 1961.

239. MAhfouz, N.: J. Obst. Ginaec. Brit. Emp. 36: 581; 1929.

240. Mahfouz, N.: J. Obst. Gynaec. Brit. Emp. 37: 566; 1930.

241. MAhfouZ, N.: J. Obst. Gynaec. Brit. Emp. 45: 405; 1938.

242. Mahfouz, N.: Bull. Soc. D’Obst. et Gynéc. 9: 131; 1957.

243. MAhfoUZ, N.: J. Obst. Gynaec. Brit. Emp. 64: 23; 1957.

244. MALPAS, P. \& cols.: J. Obst. Gynaec. Brit. Emp. 56: 49; 1949.

245. MALUF, N. S. R.: Surg. Gynec. Obst. 100: 59; 1955.

246. MarchetTi, A. A.: Am. J. Obst. Gyn. 58: 1145; 1949.

247. Marchetti, A. A. \& cols. : Am. J. Obst. Gynec. 74: 57; 1957.

248. MARION, G.: Traité d'Urologie, Masson et Cie. Paris, 3e. ed. 1928.

249. MARION, G.: J. d'Urol. 43: 261; 1937.

250. MARQUARDT, C. R.: Urol. \& Cut. Rev. 50: 6; 1946.

251. MARSHALL, V. F.: J. Urol. 58: 244; 1947.

252. MARShall, V. F. and GARDNER, J. S.: Surg. Gynec. Obst. 81: 559; 1945.

253. MARShaLL, V. F. \& cols.: Surg. Gynec. Obst. 88: 509; 1949.

254. MARTins, C. P., NEME, B. e GALluCCI, J.: Rev. Hosp. Clínicas 9: 51; 1954.

255. MARTIUS, H.: Operaciones Ginecológicas. Edit. Labor, Barcelona, 1943.

256. MAsterson, J. G.: Am. J. Obst. Gynec. 73: 359; 1957.

257. MAtern, D. I. : New Engl. J. Med. 250: 941; 1954.

258. MAthisen, W.: Surg. Gynec. Obst. 96: 255; 1953.

259. MATHISEN, W. \& cols.: J. Urol. 77: 27; 1957.

260. MAYO, C. H.: J. A. M. A. 69: 2079; 1917.

261. MAYO, C. H.: Surg. Clin. North Am. 1: 1257; 1921.

262. MAYO, C. and HENDRICKS, W. A.: Surg. Gynec. Obst. 43: 129; 1926.

263. MAYO, C. and WALTERS, W.: J. A. M. A. 82: 624; 1924.

264. MC CAUSland, A. M.: Am. J. Obst. Gynec. 79: 1110; 1960.

265. MC COMB, R. I. A.: J. Urol. 47: 240; 1942.

266. MC LEAN, D. W. and FAIS, O. G.: J. Urol. 68: 190; 1952.

267. MEdinA, J. B.: Liçôes de Clínica Ginecológica, 1961.

268. MEIGS, J. V.: Surgical Treatment of Cancer of Cervix, Grune \& Stratton, New York, 1954.

269. Meigs, J. V.: Am. J. Obst. Gynec. 72: 467; 1956.

270. Meigs, J. V. and ULFELder, H.: Am. J. Obst. \& Gynec. 68: 1272; 1954.

271. MENDES, F. A. T.: Do tratamento das fístulas vésico-vaginais pelo processo de desdobramiento. Tese Fac. Med. Univ. São Paulo, 1930.

272. MENGERT, W.: J. A. M. A. 138: 169; 1948.

273. MENGERT, W. \& cols.: Am. J. Obst. Gyn. 53: 823; 1947.

274. Michailovsky, E. und MODELSKI, W.: Ztsehr. f. Urol. 50: 233; 1957.

275. Middleton, G. W.: J. A. M. A. 97: 1536; 1931. 
276. MIKULICZ-RADECKI, F.: Zbl. f. Gynäk. 11: 195; 1931.

277. MILleR, N. F.: Am. J. Obst. \& Gynec. 44: 873; 1942.

278. MILleR, N. F.: Am. J. Surg. 64: 3; 1944.

279. Miller, N. F. and GEORGE, H.: Am. J. Obst. Gynec. 68: 436; 1954.

280. MILLIN, T.: Retropubic urinary surgery. Williams and Wilkins, Baltimore, 1947.

281. Millin, T.: Proc. Royal Soc. Med. 42: 37; 1948.

282. MILlin, T.: J. d'Urologie Med. et Chir. 55: 843; 1949.

283. Millin, T.: Proc. Royal Soc. Med. 43: 258; 1950.

284. Millin, T. and READ, C. D.: Post. Grad. M. J. 24: 3; 1948.

285. MINGAZZINI, E. : Jour. Int. Col. Surg. 12: 691; 1949.

286. MITCHELL, A. D. and VALK, W. L.: J. Urol. 69: 82; 1953.

287. MOCQUOT, P. et MORICARD, R.: Bull. Soc. Obst. Gynéc. 25: 791; 1936.

288. MOIR, J. C.: Lancet, 1: 57; 1954.

289. MOIR, J. C.: Am. J. Obst. Gynec. 71: 476; 1956.

290. MOIR, J. C. : J. Obst. \& Gynaec. Brit. Emp. 64: 342 ; 1957.

291. Am. J. Obst. Gynec. 82: 124; 1961.

292. MOIR, J. C.: The Vesico-Vaginal Fístula. Baillière Tindall \& Cox, London, 1961.

293. MONTOBвiO, V. C.: Tratado de Ginecología y de tecnica terapêutica ginecológica. $2^{\text {a }}$ ed., Editorial Labor, Barcelona, 1950.

294. MOONEN, W. A. : J. Urol. Méd. Chir. 61: 515; 1955.

295. MOORE, T. D.: J. Urol. 59: 712; 1948.

296. MOORE, E. V. \& cols.: Surg. Gyn. Obst. 102: 87; 1956.

297. MORAeS, A. e SAleS, A. A.: An. Bras. Ginec. 8; 295; 1939.

298. MUELNER, S. R.: J. Urol. 65: 805; 1951.

298-A. MUELNER, S. R. and FLEISHNER, F. G.: J. Urol. 61: 233; 1949.

299. MURPhy, J. J. and MIKUTA, J. J.: Surg. Gynec. Obst. 112: 743; 1961.

300. MURPHY, J. J. \& cols. : Surg. For. 6: 604; 1955.

301. NAUJOKS, H.: Geburtsh. und Frauenh. 15: 37; 1955.

302. NEME, B.: Temperatura Basal, Tese à Fac. Med. Univ. São Paulo.

303. NEME, B. e GalluCCI, J.: Rev. Hosp. N. S. Aparecida 6: 45; 1953.

304. NESBIT, R. M.: J. Urol. 61: 728; 1949.

305. NETO, M. e cols.: Rev. Gin. d'Obst. 103: 39; 1958.

306. NOURSE, M. H. and WISHARD, W. N.: J. Urol. 72: 374; 1954.

307. NOVAK, F.: Am. J. Obst. \& Gynec. 72: 506; 1956.

308. OCKERBLAD, N. F.: J. Urol. 57: 845; 1947.

309. ODEL, H. M. \& cols.: J. Urol. 65: 1013; 1951.

310. ORTVED, W. E.: Canad Med. Assoc. J. 71: 12; 1954.

311. OTTOW, B.: Zentr. f. Gynäk. 51: 2924; 1927.

312. PACEY, K, : J. Obst. Gyn. Brit. Emp. 56: 1; 1949.

313. PACHeCO, A. A. M.: Rev. Paul. Med. 40: 285; 1952.

314. PACHECO, A. A. M.: Rev. Paul. Med. 43: 305; 1953.

315. PARSONS, F. M. \& cols.: Lancet 263: 599; 1952.

316. PARSON, F. M. \& cols.: Brit. J. Urol. 24: 317; 1952.

317. PATTON, J. F.: J. Urol. 67: $852 ; 1952$.

318. PAUlA, A. V. e ANDRADE, C.: Rev. Ginec. d'Obst. 97: 452; 1953.

319. PEHAM, H. v. and AMREICH, J.: Operative Gynecology, Lippincott Co., Filadelfia, 1934.

320. PERnambuCO, B.: Rev. Bras. Ginec. d'Obst. 105: 309; 1959.

321. PERS, M.: Acta Chir. Scand. 109: 457; 1955.

322. PERSKY, L. \& cols.: J. Urol. 79: 463; 1958.

323. Peterson, R.: J. A. M. A. 36: 735; 1901. 
324. PHANEUf, L. E. : Am. J. Obst. \& Gynec. 31: 316: 1936.

325. Phaneuf, L. E.: Genital Fistula in Women. Am. J. Surg. 64: 3; 1944.

326. PHANEUF, L. E.: Am. J. Surg. 85: 541; 1953.

327. PHANeuf, L. E. and GRAVes, R. C.: Surg. Gynec. \& Obst. 88: 155; 1949.

328. PICHA, E. und WEGHAUPT, K.: Geburts. u. Frauenh. 15: 638; 1955.

329. PReston, P. G.: J. Obst. Gynaec. Brit. Emp. 58: $282 ; 1951$.

330. PRIESTLEY, J. T. and STROM, G. W.: J. Urol. 50: $210 ; 1943$.

331. PYRAH, L. N.: Ann. R. Coll. Surg. Engl. 14: 169; 1954.

332. PYRAH, L. N.: J. Urol. 78: 683; 1957.

333. PYRAH, L. N. and RAPER, F. P.: Brit. J. Urol. 42: 337; 1955.

333-a. PELTIER DE QUEIROZ, A.: Comun. pessoal, 1961.

334. RACK, F. G.: J. A. M. A. 152: 516; 1953.

335. RANDALL. L. M. and HARDWICK, R. S.: Surg. Gynec. Obst. 58: 1018; 1934.

336. RAWLS, R. M.: in CURTIS, A. H.: Obstetrics and Gynecology. III vol. Saunders Co., Filadelfia, 1934

337. READ, C. D.: Proc. Royal Soc. Med. 43: 255; 1950.

338. READ, C. D.: Am. J. Obst. Gynec. 59: 1260; 1950.

339. REEB M.: Bull. Soc. d’Obst. et Gynec. 24: 192; 1935

340. REICH, W. J. and WILKEY, J. L.: Urol. \& Cutan. Rev. 47: 160; 1943.

341. REICHENMilleR, H.: Zbl. f. Gynäk. 62: 1458; 1938.

342. REyes, N. V.: Rev. Méd. Peruana 21: 183; 1949

343. RIBA, L. W.: J. Urol. 67: 284; 1952.

344. RIBEIRO, E. R.: An. Bras. Ginec. 48: 1; 1959.

345. RICHES, E. W.: Brit. J. Urol. 21: 51; 1949.

346. RobertS, M. : J. Obst. \& Gynaec. Brit. Emp. 51: 519; 1944.

347. ROBERTS, H.: Brit. J. Radiol. 25: 253; 1952.

348. ROSEMBERG, M. L. : J. Urol. 70: 569; 1953.

349. ROSENFELD, S. and BERGMAN, H.: Obst. Gyn. 4: 562; 1954.

350. RUdGe, W. S.: Rev. Obst. Ginec. S. Paulo 3: 217; 1938.

351. RUDGE, W. S.: An. Bras. Ginec. 8: 295; 1939.

352. RUDGE, W. S.: Contribuição para o tratamento das Fístulas Uro-genitais pela plástica do desdobramento. Tese Fac. Med. Univ. São Paulo, 1941.

353. RUDGE, W. S. : An. Bras. Ginec. 18: 219; 1944.

354. RUdGe, W. S.: Rev. Paul. Med. 31: 1; 1947.

355. RUDGE, W. S. e FERREIRA, F.: Mat. Infância, 6: 1; 1950.

356. RUSCH, S. and HAGER, B. H.: In Campbell: Urology. W. B. Saunders Co., Philadelphia, 1954 .

357. RUSSELL, C. S.: J. Obst. Gynaec. Brit. Emp. 63: 481; 1956.

358. SAlaber, J. A. y GUIXÁ, H. L.: La Prensa Med. Argent. 41: 247; 1954.

359. SAlgADO, C.: An. Bras. Ginec. 16: 7; 1943.

360. SALGADO, C.: An. Bras. Ginec. 27: $349 ; 1949$.

361. SAlgado, C.: Rev. Assoc. Med. Minas Gerais. 1: 389; 1950.

362. SALGADO, C.: An. Bras. Ginec. 37: 129; 1954.

363. SAlgado, C.: Memórias apresentada à Acad. Nac. Medicina, 1960.

364. SAlles, AQUino, A. e COURI, A. A.: An. Bras. Ginec. 22: 263; 1946.

365. SAlmoN, U. J. \& cols. : Am. J, Obst. Gyn. 42: 845; 1941.

366. SANT'ANNA, J.: Rev. Ginec. d'Obst. 1: 11; 1932.

367. SANT'ANNA, J.: Rev. Ginec. d'Obst. 33: 11; 1939.

368. SARGENT, J. C. : J. Urol. 73: 520; 1955.

369. SAUER, H. R. \& cols.: Surg. Gynec. Obst. 89: 299; 1949. 
370. SCOTt, W. W.: Am. J. Obst. Gynec. 68: 1301; 1960.

371. SEXTON, Jr. G. L.: Obst. \& Gynec. 17: 739; 1961.

372. SHAW, E. C. : J. Urol. 70: 91; 1953.

373. SHAW, W.: Surg. Gynee. Obst. 88: 11; 1949.

374. SJOVALL, A.: Acta Obst. \& Gynec. Scand. 25: 385; 1946.

375. SKANSE, B.: J. Urol. 73: 62; 1955.

376. STAMEY, T. A.: Surg. Gyn. Obst. 103: 736; 1956.

377. Stamey, T. A. and SCOTt, W. W.: Surg. Gyn. obst. 104: 11; 1957,

378. STEVEnS, A. R.: J. Urol. 46: 57; 1941.

379. STEWARD, M. and WEBSTER, A.: Obst. \& Gynec. 3: 169; 1954.

380. Stieve, H.: Dtsch. Med. Wschr. 1: 130; 1928.

381. STOECKEL, W.: Zbl. f. Gynäk. 45: 17; 1921.

382. StOECKEL, W.: Tratado de Obstetricia, 2a ed. Ed. Modesto Uson, Barcelona, 1932.

383. STOECKEL, W.: Gynäkologische Urologie, in Veit Stoeckel-Handbuch der Gynäkologie. $3^{a}$ edicão X vol. II e III tomos, J. F. Bergmann, Munique, 1938.

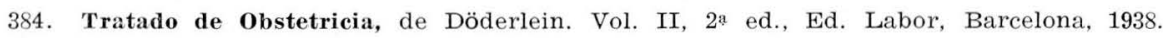

385. StokCKel, W.: Tratado de Ginecologia. 2a ed., Ediciones Morata, Madrid, 1948.

386. Stomington, O. G. and EISEman, B.: J. Urol. $76: 74 ; 1956$.

387. STrean, G. J.: Am. J. Obst. Gynec. 64: 1322; 1952.

388. TAVolaro, M.: Med. Moderna, 3: 79; 1950.

389. TE LINDE, R. W.: Ann. Surg. 126: 64; 1947.

390. TE LINDE, R. W.: Operative Gynecology. J. B. Lippincott Co. Philadelphia, 1946.

391. TE LINDE, R. W.: Am. J. Obst. Gynec. 60: 273; 1950.

392. TE LINDE, R. W.: Am. J. Obst. Gynee. 74: 1305; 1957.

393. THOMAS, G. B.: J. Obst. \& Gynaec. Brit. Emp. 52: 262; 1945.

394. Thompson, D. J.: J. Obst. \& Gynaec. Brit. Emp. 52: 271; 1945.

395. ThOMPSON, G. J. and COUNSEller, V. S.: J. Intern. Coll. Surgeons 25: 479; 1951.

396. THOMS, H.: Am. J. Obst. Gynec. 42: 947; 1941.

397. THOMS, H. and WYATT, R. H.: Am. J. Obst. Gynec. 59: 429; 1950.

398. THOUVENOT, G. et MARNEFFE, M.: Gynéc. et Obstet. 56: 34; 1957.

399. TOWNSEND, W. W.: Surg. Gyn. Obst. 2: 248; 1915.

400. TWOMBLY, G. H. and MARSHALL, V. F.: Surg. Gynec. Obst. 83: 348; 1946.

401. UlLery, J. C.: Stress incontinence in the female. Grune and Stratton, New York, 1953.

402. ULM, A. H. : J. Urol. 79: 21; 1958.

403. VAZ, O.: Bol. Col. Bras. Cir. 25: 227; 1952.

404. VERNET, E. G.: Incontinencia urinaria en la mujer. Ed. Paz Moltalvo, Madrid, 1955.

405. Visscher, M. B. \& col.: Am. J. Physiol. 142: 550; 1944.

406. YOUNG, H. M.: J. Urol. 55: 641; 1946.

407. Youssef, A. F.: Am. J. Obst. Gynec. 73: 759; 1957.

408. YOUSSEF, A. F.: Gynecological Urology. Ch. Thomas Springfield Ill. 1960.

409. WALters, W.: Arch. Klin. Chir. 167: 589; 1931.

410. WARD, G. G.: J. Mt. Sinai Hosp. 10: 176; 1943.

411. WAtkins, R. E.: Am. J. Obst. Gynec. 18: 361; 1929.

412. WAtson, W. P.: Brit. Med. J. 2: 566; 1924.

413. WEHNER, W. und BROSIG, W.: Zeits. f. Urologie 50: $564 ; 1957$.

414. Weinberg, A. and SCADron, S. J.: Am. J. Obst. Gyn. 52: 255; 1946.

415. WENIG, K.: Zentr. f. Gynäk. 80: 1728; 1958.

416. WERNECK, J.: An. Bras. Gin. 30: 207; 1950.

417. WERNER, P. and SEDERL, J.: Gynaecologia 138: 575; 1954.

418. WEYRAUCH, H. M. and ROLAND, S. I.: J. Urol. 79: 255; 1958. 
419. WEYRAUCH, H. M. and YOUNG, B. W.: J. Urol. 67: 880; 1952.

420. Wharton, L. R.: Gynecology \& Female Urology. W. B. Saunders Co. Filadelfia, 1944.

421. WhaRTON, L. R.: Am. J. Obst. Gyn. 66: 1121; 1953.

422. WHISENAND, J. M. and MOORE, V.: J. Urol. 65: 564; 1951.

423. WILKINSON, A. W.: Brit. J. Urol. 24: 46; 1952.

424. Williams, G. A.: Am. J. Obst. Gynec. 58: 1066; 1949.

425. WOOD, J. y VELASQUEZ, V.: Informação pessoal, 1961.

426. WOODRUFF, L. M. \& cols. : J. Urol. 67: 873; 1952.

427. Zarate, E.: Bol. Soc. Obst. Gin. B. Aires. 17 : 485; 1938. 